Universidad de Lima

Facultad de Comunicación

Carrera de Comunicación

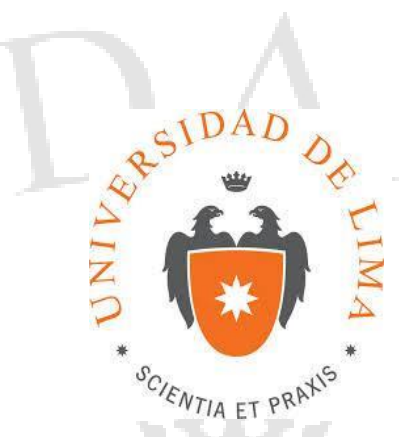

\title{
ANÁLISIS DE LA GESTIÓN DEL CLIMA LABORAL EN LOS ORGANISMOS REGULADORES DE LIMA: CASO OSIPTEL
}

Trabajo de Investigación para optar el Título Profesional de Licenciado en

Comunicación

\section{Jamil Humberto Sheput Torrealva}

Código: 20101885

\author{
Asesor \\ Julianna Ramirez Lozano
}

Lima - Perú

Enero de 2017 


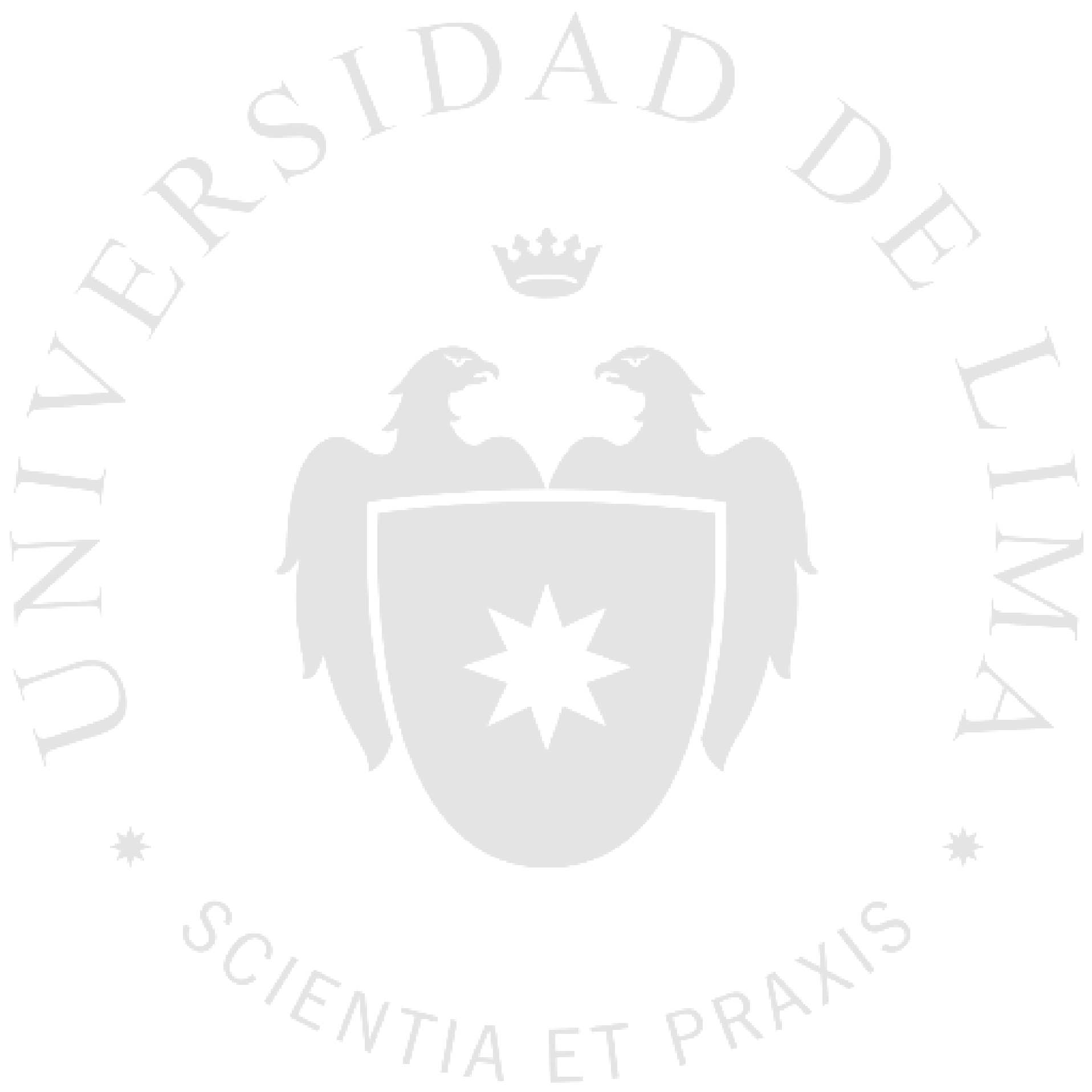



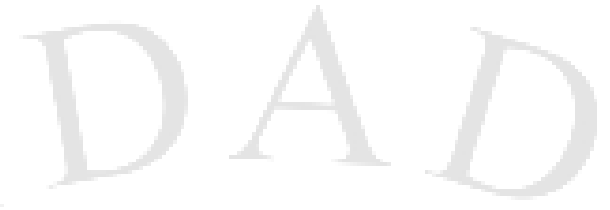

ANÁLISIS DE LA GESTIÓN DEL CLIMA LABORAL EN LOS ORGANISMOS REGULADORES DE LIMA: CASO OSIPTEL

NTIA ET

ii 
RESUMEN: La gestión del clima laboral es un aspecto fundamental para toda organización. Desde hace aproximadamente 10 años, los estudios sobre clima laboral se han expandido de empresas privadas a PYMES, instituciones educativas y de salud, organizaciones públicas y estatales, entre otras.

La presente investigación analizó la gestión del clima laboral en el Organismo Supervisor de Inversión Privada en Telecomunicaciones (OSIPTEL), organismo regulador peruano, con el fin de continuar con la expansión previamente mencionada. Se realizaron encuestas y entrevistas a profundidad a colaboradores de distintos rangos de la institución, mediante las cuales se determinaron las características de la gestión y la percepción propia y colectiva del objeto de estudio.

Palabras clave: Clima laboral, organismo regulador, comunicación interna, comunicación en el estado.

ABSTRACT: Management of the organizational climate is a fundamental aspect for every organization. For about 10 years, the studies on organizational climate have breached from private companies to SME, health and educational institutions, public and state organizations, among others.

The following article analyzes the Supervisory Body of Private Investment in Telecommunication (OSIPTEL)'s management of its organizational climate, in order to continue with the expansion mentioned above. Surveys and in-depth interviews were conducted to the institution's employees, in order to identify the characteristics of the climate's management and it's individual and collective perception.

Keywords: Organizational climate, regulatory body, internal communication, state communication. 


\section{INTRODUCCIÓN}

Los colaboradores y altos mandos de organismos estatales y reguladores afirman que el clima laboral en sus instituciones no es gestionado adecuadamente, ya que son organizaciones muy orientadas hacia fuera, es decir, enfocadas en sus grupos de interés externos. Caracterizadas por alta rotación del personal, amplia distancia de poder, entendida como la medida en que los miembros menos poderosos de las organizaciones aceptan y esperan que el poder se distribuya de forma desigual, poco compromiso por parte de los altos mandos con los públicos internos; y una comunicación vertical descendente, la cual pasa por varios canales antes de llegar de los gerentes a los subordinados, cabe preguntarse si estas organizaciones pueden gestionar el clima laboral dentro de ellas de manera positiva o si, inevitablemente, la percepción de quienes las conforman sobre el mismo será permanente.

El Organismo Supervisor de Inversión Privada en Telecomunicaciones (OSIPTEL), regulador de los sectores de telefonía, televisión e Internet, es una de estas organizaciones estatales que sí gestiona de manera positiva su clima laboral. Fundado en 1991, Osiptel cuenta con 25 oficinas a nivel nacional, 2 de ellas ubicadas en la región Lima. El regulador está conformado por 11 gerencias y un total de 572 colaboradores en todo el país, trabajando 417 de ellos en las sedes de la capital.

Las características observadas en la gestión del clima laboral de esta organización incluyen un clima laboral enfocado en el bienestar del colaborador y el reconocimiento de sus méritos, una cultura organizacional, entendida como el conjunto de valores y creencias que interactúan en una institución, donde los colaboradores de cada gerencia, llamados 'osiptelinos', forman vínculos de amistad sólidos al punto de considerarse miembros de una familia; y una comunicación interna horizontal, donde los subordinados y altos mandos tienen facilidad para comunicarse entre sí. Asimismo, la organización cuenta con seis valores institucionales, los cuales se difunden a través de actividades de integración y se aplican en la vida laboral diaria: solidaridad, confianza, orgullo, sentido de la unidad, imparcialidad y credibilidad. 
Para lograr esto, Osiptel, a través de la Gerencia de Administración y Finanzas (GAF), implementó el año 2014 el 'Modelo de Gestión de Recursos Humanos', mediante el cual se trabajan diversas estrategias que refuerzan la comunicación organizacional de la institución. El modelo incluye un 'Plan de Mejora de Clima Laboral' anual, el cual evalúa y gestiona el clima laboral, la comunicación interna y la interiorización los valores institucionales; un 'Plan de Bienestar' anual, el cual se enfoca en el bienestar, salud y desarrollo del colaborador; y una serie de actividades de integración donde se reconocen méritos a nivel laboral y personal de los colaboradores. Como parte del modelo, Osiptel ha implementado un equipo encargado de velar por el buen clima laboral dentro de cada gerencia denominado 'Doctores del Clima'. Cada gerente designa a un colaborador, basado en sus capacidades empáticas y comunicativas, que sirve de nexo entre los altos mandos y los subordinados; y comunica los problemas, dudas y méritos que acontecen en cada área para poder resolverlos o reconocerlos de la mejor manera posible.

Producto de estos esfuerzos, Osiptel ha logrado consolidar un buen clima laboral y establecerlo como una de sus fortalezas, constituyéndolo como parte de la imagen institucional del regulador. En los dos últimos años, Osiptel se ha posicionado por encima del promedio de porcentaje de otras instituciones estatales en la encuesta 'Trust Index' del instituto Great Place To Work, la cual evalúa la satisfacción del colaborador respecto al clima laboral en organizaciones privadas y públicas de acuerdo a seis factores: aceptación general, credibilidad, respeto, imparcialidad, orgullo y camaradería. En 2015, Osiptel, junto a COFIDE (antes Corporación Financiera de Desarrollo), fue una de las dos organizaciones del Estado que recibieron el premio Great Place To Work (el cual reconoce a las mejores instituciones privadas y públicas para trabajar a nivel nacional según el clima laboral que estas poseen) al lograr un 77\% de satisfacción en la encuesta de Clima Laboral. El promedio del resto de organizaciones estatales fue de 70\%. En 2016 Osiptel obtuvo un 73\% de satisfacción en la misma evaluación mientras que el promedio del resto de instituciones públicas disminuyó un punto porcentual.

En el siguiente gráfico se muestra la estructura organizacional del regulador. 
Gráfico 1: Estructura organizacional de Osiptel.

\section{Estructura Organizacional}

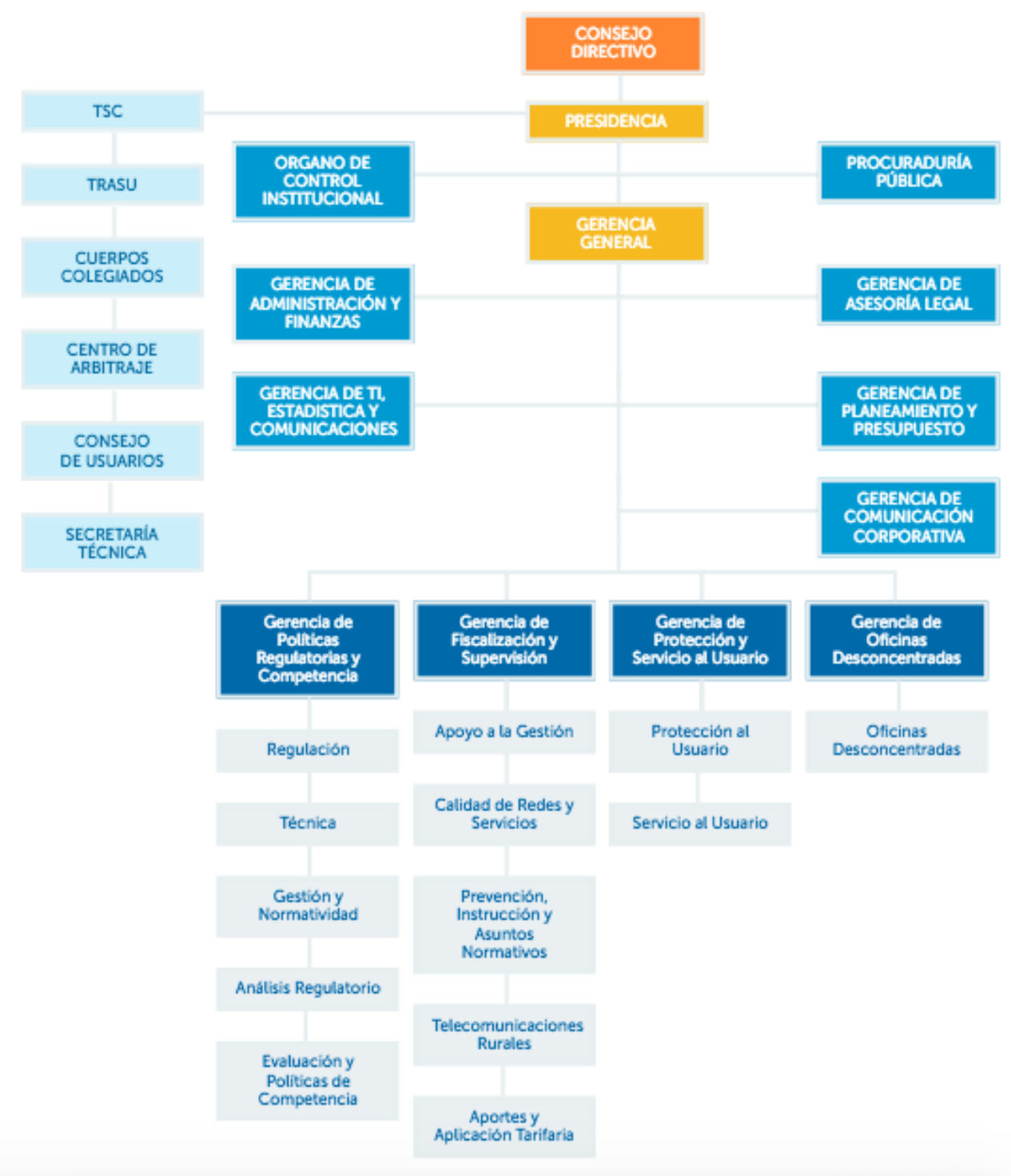

Fuente: www.osiptel.gob.pe. Revisado en enero de 2017.

El presente artículo tuvo como objetivo general demostrar que los organismos reguladores en Lima pueden gestionar adecuadamente el clima laboral dentro de ellos. Como objetivos específicos, se planteó el mostrar el análisis de las características de la gestión del clima laboral en Osiptel de acuerdo a la percepción de los colaboradores; y realizar un análisis comparativo con lo propuesto en el 'Modelo de Gestión de Recursos Humanos' para determinar la concordancia entre ambos. Asimismo, se propuso diagnosticar el alcance de la difusión del 'Modelo de Gestión de Recursos Humanos' y su influencia dentro del ambiente de trabajo en la organización. Finalmente, se 
estableció como objetivo específico plantear recomendaciones para contrarrestar las debilidades encontradas en la gestión del clima laboral.

El propósito de esta investigación fue dar a conocer que hay organismos reguladores que sí gestionan el clima laboral de manera adecuada, lo cual sirve para que los profesionales del sector público pongan mayor interés en tratar este tema en cada una de sus organizaciones. Asimismo, el presente artículo será de utilidad para los profesionales de la comunicación corporativa y gestión de recursos humanos.

La primera definición de clima laboral en la que se basó esta investigación es la de Richard Hall (1996), quien afirma que el clima laboral es un conjunto de propiedades del ambiente laboral, percibidas directa o indirectamente por el empleado, las cuales se supone son una fuerza que influye en su conducta. Hall le da un valor agregado al uso de la palabra "percepción" en su definición al añadirle el adverbio “indirectamente", indicando que el clima laboral de una organización no solo depende de lo que el colaborador percibe conscientemente, sino de todo lo que da por garantizado o pasa desapercibido para él. Esta definición abarcó el tema de percepción del primer objetivo específico de esta investigación y los aspectos de difusión y comunicación del segundo objetivo del presente trabajo, al plantear la posibilidad que lo propuesto en el modelo se aplique en la institución de forma más tácita que explícita.

La segunda definición de clima laboral con la que se trabajó es la de Forehand y Gilmer (1964) quienes definen el clima laboral como el conjunto de características permanentes que describen una organización, la distinguen de otra e influye en el comportamiento de las personas que la forman. Este enfoque se utilizó especialmente para cuestionar lo permanente de las características del clima laboral en un organismo regulador, especialmente cuando se hace una transición de no tener un modelo de clima laboral escrito a tenerlo.

La tercera definición en la cual se basó la siguiente investigación es la de Litwin y Stringer (1978), representantes del enfoque sintético. Ellos definen el clima laboral como el efecto subjetivo percibido del sistema, que forman el estilo informal de los administradores y de otros factores ambientales importantes sobre las actividades, las creencias, los valores y la motivación de las personas que trabajan en una 
organización dada. Este enfoque contribuyó para la aplicación de las herramientas metodológicas, evaluando la subjetividad de cada colaborador al momento de describir el clima laboral de la institución.

A estas teorías se sumaron los aportes de Fernando Toro (2001), quien afirma que la percepción de los colaboradores sobre el clima laboral puede ser compartida y no individual; y el de Olga Anzola (2003), quien resalta que el clima laboral es un factor diferencial para toda organización. Se utilizó la teoría de Toro para compararla con la subjetividad propuesta por Litwin y Stringer, mientras que el aporte de Anzola sirvió para analizar el impacto de la gestión del clima laboral en la identidad corporativa del regulador.

Finalmente, la investigación se complementó con los conceptos de comunicación interna, definida por Benito Berceruelo (2011) como el flujo de mensajes que nacen, se reproducen y circulan en el seno de las organizaciones; y de identidad corporativa, definida por Joan Costa (2009) como el ADN de la empresa donde se encuentra la singularidad, la capacidad y potencial desarrollo futuro de la misma; y de imagen corporativa, definida por Nicholas Ind (1990) como la forma en la que el público percibe a una organización a través de la acumulación de todos los mensajes recibidos. 


\section{METODOLOGÍA}

Para la presente investigación, se aplicó una metodología de enfoque mixto. Para la parte cuantitativa, se realizaron 40 encuestas (ver anexo 1) de opción múltiple a gerentes y colaboradores de todas las áreas de la institución, donde se evaluaron aspectos del clima laboral como la confianza entre colaboradores y gerentes, el manejo de errores, la valoración del trabajo del colaborador y la comunicación interna. También se evaluó la extensión del conocimiento y la percepción de los colaboradores en cuanto al 'Modelo de Gestión de Recursos Humanos'. Se analizaron los resultados en base a la gerencia a la que pertenecen los encuestados y al tiempo de servicio en la organización. La dotación a la fecha de la aplicación de la encuesta fue de 417 colaboradores.

Por el lado cualitativo, se realizaron 06 entrevistas a profundidad (ver anexo 3) a gerentes y colaboradores de distintas gerencias de Osiptel, donde se indagó en su percepción personal sobre el clima laboral en la institución y sobre su conocimiento y opinión del 'Modelo de Gestión de Recursos Humanos'. Esta última parte se realizó para comparar el concepto personal de la alta dirección con la del plan aplicado en la organización y poder determinar las dificultades que impiden que el concepto de clima laboral se integre en la alta dirección.

Asimismo, se realizaron 03 entrevistas a profundidad a los 'Doctores del Clima', donde se preguntó por su percepción sobre el clima laboral, la extensión del conocimiento del modelo de gestión aplicado en la institución y la importancia de su función como 'Doctores del Clima’ para el bienestar de la organización. 


\section{RESULTADOS}

\subsection{Características del Clima Laboral de Osiptel}

Los colaboradores encuestados y entrevistados afirman que el clima laboral en Osiptel, en general, es positivo. Los miembros de una misma gerencia se consideran unos a otros como familia, debido a los fuertes lazos que los unen. La distancia de poder es baja; y la disponibilidad y accesibilidad de los altos mandos a escuchar las opiniones y atender las necesidades de las personas a su cargo es reconocida como una de las fortalezas de la organización.

Para mantener esta percepción positiva, cada gerencia tiene como parte de sus metas anuales incrementar el porcentaje de clima laboral dentro de su área. Para ello, los altos mandos presentan a la Gerencia de Administración de Finanzas (GAF) un 'Plan de Clima Laboral' por área, donde se describen acciones comunicacionales y de integración que se desarrollan y ejecutan en un periodo de tiempo determinado en base a los resultados de la encuesta de clima laboral. Todos los gerentes presentan sus planes, mas no se hace un seguimiento, hasta el momento de la evaluación anual de clima laboral, si estos se cumplieron o no.

Los seis valores institucionales están interiorizados de forma efectiva en la organización. Un $80 \%$ de colaboradores y gerentes señalaron que conocen todos los valores, mientras que el $20 \%$ restante conoce casi todos. Cada actividad institucional interna trabaja un valor en su concepto y busca reforzarlo. Además, en distintas partes de la institución se colocan banners con la definición y descripción de un valor, al igual que la razón por la cual éste pertenece al Osiptel. Estas acciones han logrado que los valores se posicionen en la mente del colaborador y se practiquen en la vida laboral diaria sin necesidad de difundirlos o explicarlos de manera teórica. Además, los valores forman parte del proceso de selección del personal, jugando un papel importante al momento de incorporar a un nuevo miembro al regulador.

"Siempre se tiene que reforzar el tema de valores y nosotros lo hemos asociado a la mayoría de las actividades que hacemos. Se debe encontrar un punto medio 
en que haya un factor de recordación y puesta en práctica en el colaborador; y no hostigarlo con tantos mensajes".

Miguel Torres, jefe de Recursos Humanos de la Gerencia de Administración y Finanzas (GAF) de Osiptel.

La valoración del trabajo y el reconocimiento al colaborador fueron resaltados por los entrevistados. Osiptel tiene diversas acciones y actividades donde se recompensa o reconoce el esfuerzo del colaborador. Cada gerencia premia al mes a un colaborador diferente que ha destacado en un aspecto de su vida laboral o personal. Esta valoración fideliza a los osiptelinos y contribuye positivamente al clima laboral en la organización.

"Hemos trabajado con todos los jefes, gerentes y subgerentes el tema de Gift Work, es decir, cómo puedes darle un regalo a tu equipo, el cual puede ser tiempo libre, preocupación por ellos, el interés y reconocimiento del trabajo bien logrado, etc.".

Ximena García, encargada de Comunicación Interna, Clima y Bienestar de la Gerencia de Administración de Finanzas (GAF) de Osiptel.

El gráfico a continuación muestra la percepción de los colaboradores sobre la valoración de su trabajo de acuerdo al tiempo que llevan formando parte de la institución. Como se observa en el mismo, los colaboradores con más tiempo en la organización son los que más valorados se sienten. 
Gráfico 2: Valoración del trabajo por compañeros y superiores de acuerdo al tiempo trabajado en la institución.

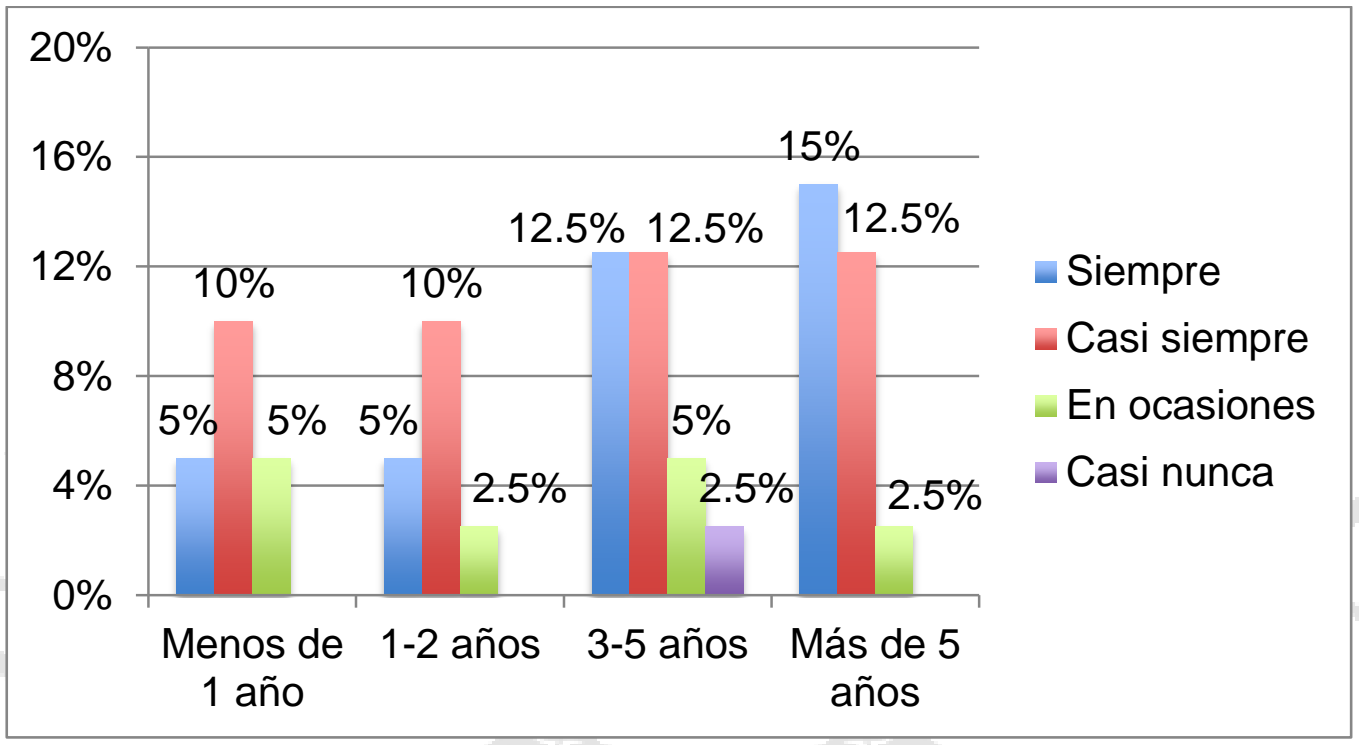

Fuente: Elaboración propia

La solidaridad es otro factor destacado por los osiptelinos. Cuando se incorpora un nuevo miembro a una gerencia, todos los demás colaboradores se encargan de hacerlo sentir bienvenido y de enseñarle el manejo adecuado de los programas de computadora necesarios para el desarrollo de sus labores. Asimismo, algunas gerencias comparten equipos, herramientas de trabajo e incluso alimentos cuando es necesario; y se brindan regalos entre ellos por fechas especiales como cumpleaños, matrimonios y nacimientos.

"Llegué acá a suplantar por dos meses. Desde que llegué, todo el mundo me trató de enseñar. Yo no sabía los sistemas y la secretaria de contrataciones me decía “ven, yo te voy a enseñar”. Acá hacen que sea agradable tu tiempo".

Karen Calderón, 'Doctora de Clima' de Procuraduría Pública de Osiptel.

Otro valor que destaca es el orgullo por pertenecer al Osiptel, el cual se manifiesta especialmente en las redes sociales de los colaboradores. Tanto altos mandos como subordinados comparten en Facebook, Instagram y Twitter los reconocimientos que les da el Regulador, resaltando el orgullo de formar parte de la organización y agradeciendo por el premio otorgado. Estas publicaciones permiten ver al círculo social 
de cada persona el aprecio del colaborador a la institución y generan comentarios positivos hacia ella.

"Por el Día de la Madre, dimos una tarjeta y unas bolsitas personalizadas. Yo lo publiqué en mis redes sociales y me comentaron “oye, qué bacán tu institución”. Roxana Sánchez, 'Doctora del Clima' de la Gerencia de Oficinas Desconcentradas (GOD) de Osiptel.

La comunicación interna fue el factor más observado por los colaboradores. Para algunos, ésta es eficiente debido a la horizontalidad de la misma y al acercamiento de los gerentes con los colaboradores, destacando el hecho que ellos comunican directamente a su equipo de trabajo todo lo discutido en el Comité de Gerentes ${ }^{1}$ o a través de los jefes de área. No obstante, para otros, esta comunicación en cascada, entendida como la comunicación desde la alta dirección hacia los demás niveles de la organización, es deficiente, ya que no a todos los colaboradores se les brinda la información de lo conversado en la mencionada reunión de forma adecuada. La fluidez de la comunicación entre colaboradores de un mismo área y entre áreas también se puso en cuestión, afirmándose que ésta solo se da en ocasiones.

"En comunicación, hay temas que se pueden mejorar. Muchas veces, se toman decisiones en el Consejo Directivo y no necesariamente bajan en forma adecuada a los diferentes estamentos de la institución".

Humberto Sheput, Gerente de la Gerencia de Protección y Servicio al Usuario (GPSU) de Osiptel.

El siguiente gráfico muestra los resultados de la percepción sobre la fluidez de la comunicación. Un 45\% de encuestados afirmaron que la comunicación interna sólo es fluida en ocasiones y un $10 \%$ resaltó que la comunicación casi nunca es efectiva.

${ }^{1}$ Reunión semanal de gerentes, subgerentes, jefes y miembros de la alta dirección donde se discuten los temas y actividades más importantes a corto y largo plazo. 
Gráfico 3: Frecuencia de fluidez de la comunicación entre colaboradores.

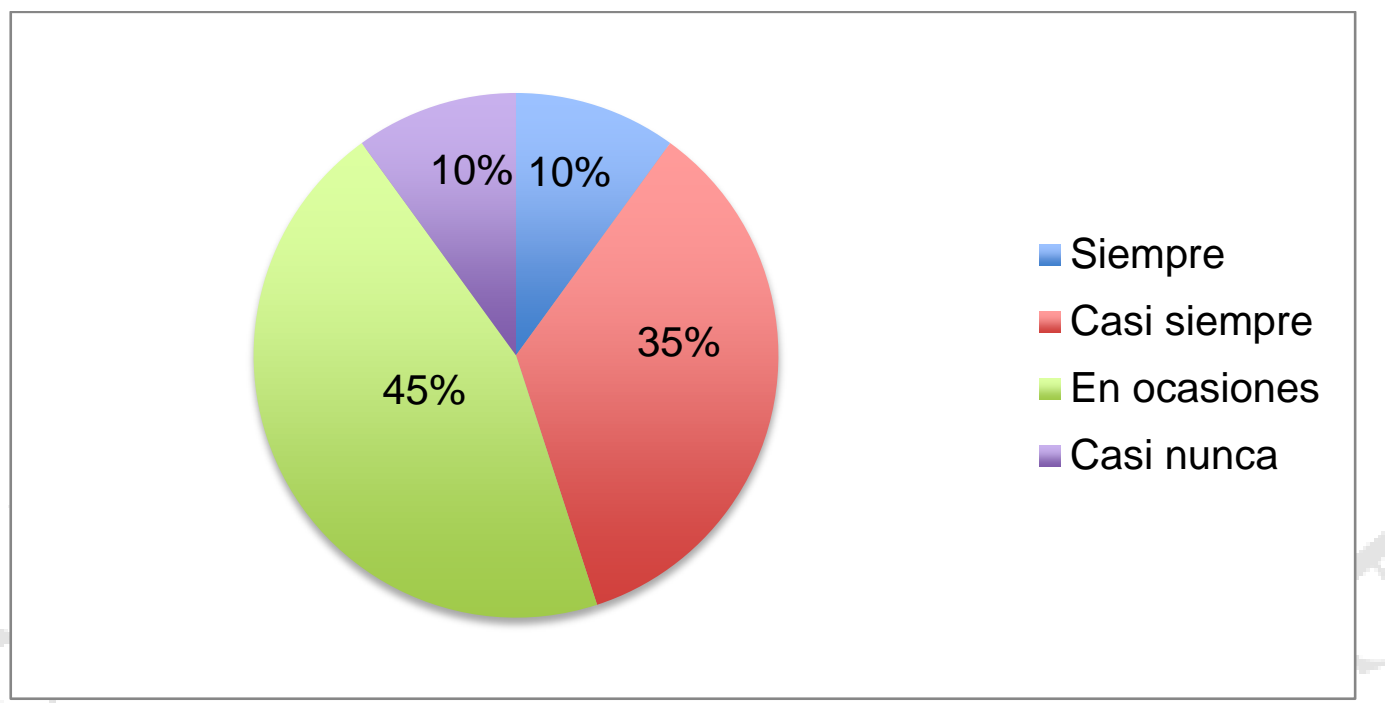

Fuente: Elaboración propia

Algunos entrevistados afirmaron que si bien el ambiente de trabajo en general es positivo, existen 'microclimas' dentro de la institución. Los equipos de cada gerencia se consideran una familia y forman vínculos estrechos y sólidos. Sin embargo, son pocas las gerencias que interactúan una con otra; y no todos los colaboradores se conocen entre sí, por lo cual este vínculo no necesariamente llega a formarse a nivel intergerencial. Además, algunos colaboradores afirman que la distribución de la carga laboral es desigual, lo cual causa envidia o recelo entre ellos.

"En cada gerencia, el clima laboral es bueno y la gente está contenta haciendo su trabajo. Pero una gerencia no necesariamente conversa con la otra. Falta una visión de clima laboral más institucional y menos particular"

Lenka Zajec, Gerente de la Gerencia de Comunicación Corporativa (GCC) de Osiptel.

Por otro lado, la percepción sobre los 'Doctores del Clima' es positiva, ya que permiten que el colaborador exprese sus ideas y cuente sus problemas con libertad. Los doctores trabajan la confianza, la escucha y la empatía entre colaboradores, factores que, según las herramientas aplicadas, necesitan reforzarse en la institución. La implementación de este cargo ha logrado, además, que los colaboradores de menor rango, especialmente aquellos que recién ingresan, pierdan el miedo de decir lo que sienten o piensan; y que las diferencias de mentalidad y formas de expresión entre altos 
mandos y subordinados no tenga un impacto negativo en el equipo como conjunto ni en el colaborador como individuo. No obstante, los doctores consideraron que es necesario reunirse más seguido entre ellos y con el equipo de GAF para discutir temas de interés relacionados al clima laboral e implementar nuevas estrategias de comunicación con los colaboradores, ya que las reuniones que tienen actualmente son escasas.

\subsection{Conocimiento, aplicación y comparación de percepciones del 'Modelo de Gestión de Recursos Humanos’ en Osiptel}

En las entrevistas resaltó que el clima laboral actual de Osiptel no es reciente. Factores como la solidaridad, el orgullo, la fidelización, la baja distancia de poder, la comunicación horizontal y las actividades de integración existían desde la fundación de la institución. Sin embargo, los colaboradores afirmaron que la implementación del 'Modelo de Gestión de Recursos Humanos' permitió estructurar y darle sentido a estas características ya establecidas, añadiendo a la vez nuevas filosofías, conceptos y objetivos que permitieron solidificar el buen clima laboral y convertirlo en una pieza fundamental de Osiptel.

"Desde que yo ingresé a Osiptel, a pesar de haber menos gente, siempre ha habido un muy buen clima laboral. De repente, puede que ahora la gente lo tenga más claro, gracias al modelo. Pero siempre ha sido así."

Roxana Sánchez, Doctora del Clima de la Gerencia de Oficinas Desconcentradas (GOD).

Asimismo, los colaboradores están de acuerdo con la filosofía impartida en el modelo y lo consideran útil para la organización ya que permite a los altos mandos gestionar mejor los talentos y que cada miembro de los grupos de trabajo se sienta cómodo y bien de trabajar en donde está. También señalan que el modelo ha reforzado la identidad corporativa del regulador y ha trabajado los aspectos de clima laboral, cultura corporativa y valores institucionales de manera complementaria, a la vez que ha permitido ver la importancia de la retención de talentos y el reconocimiento al colaborador. 
Respecto a la difusión, un $77.5 \%$ de osiptelinos conoce que hay un 'Modelo de Gestión de Recursos Humanos', mas solo un $12.5 \%$ lo conoce a profundidad. La difusión del modelo ha sido limitada por la propia Gerencia de Administración y Finanzas (GAF), con el fin de mantener el factor sorpresa para las actividades. Sin embargo, tanto gerentes como 'Doctores del Clima' consideran necesario incrementarla con el fin de poder conocer más sobre la aplicación y el impacto del modelo en toda la organización. Por otro lado, a pesar de la escasa difusión del modelo, los osiptelinos conocen una mayoría de aspectos de la cultura organizacional y casi todos los valores institucionales gracias a las actividades de integración y acciones de comunicación realizadas.

"Yo tengo mis recelos respecto a dar a conocer todo el plan. Se pueden difundir las grandes dimensiones que vamos a trabajar, mas no las actividades puntuales, porque mi preocupación es quitar el factor sorpresa." Ximena García, encargada de Comunicación Interna, Clima y Bienestar de la Gerencia de Administración de Finanzas (GAF).

El siguiente gráfico muestra la opinión sobre la difusión del modelo. La mayoría de colaboradores encuestados considera que éste se ha difundido solo en pocos aspectos, mientras que otros consideran que sí se ha comunicado una mayoría de sus elementos

Gráfico 4: Magnitud de la difusión del 'Modelo de Gestión Recursos Humanos'.

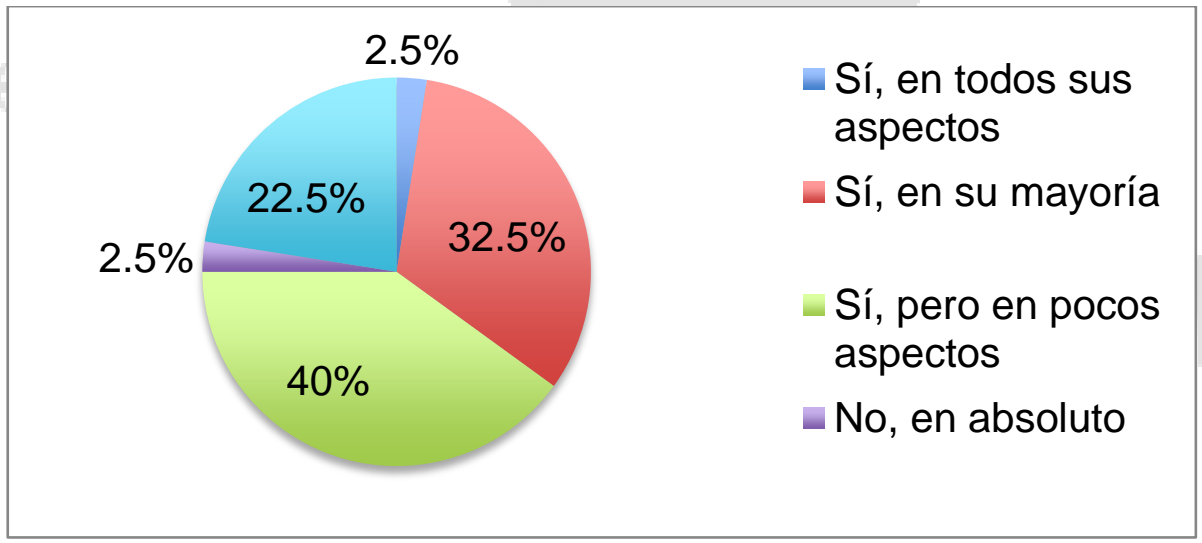

Fuente: Elaboración propia. 
Finalmente, el equipo de Osiptel considera que sí existe concordancia entre lo que el modelo propone y lo que se vive en la institución, mas no en un alto grado. Los esfuerzos del equipo de GAF, los 'Doctores del Clima' y el compromiso de los gerentes son destacados por los colaboradores. Sin embargo, factores como la comunicación interna y los microclimas por gerencia deben trabajarse para que el modelo se cumpla en su totalidad.

El siguiente gráfico muestra los resultados sobre la concordancia entre lo propuesto en el 'Modelo de Gestión de Recursos Humanos' y la situación laboral actual en Osiptel según el tiempo de servicio del colaborador en la institución. Se observa que a mayor es el tiempo de servicio, mayor es la concordancia percibida entre el modelo y lo que se vive en la institución.

Gráfico 5: Magnitud de la concordancia entre lo propuesto en el 'Modelo de Gestión de Recursos Humanos' y la situación laboral en Osiptel según el tiempo trabajando en la institución.

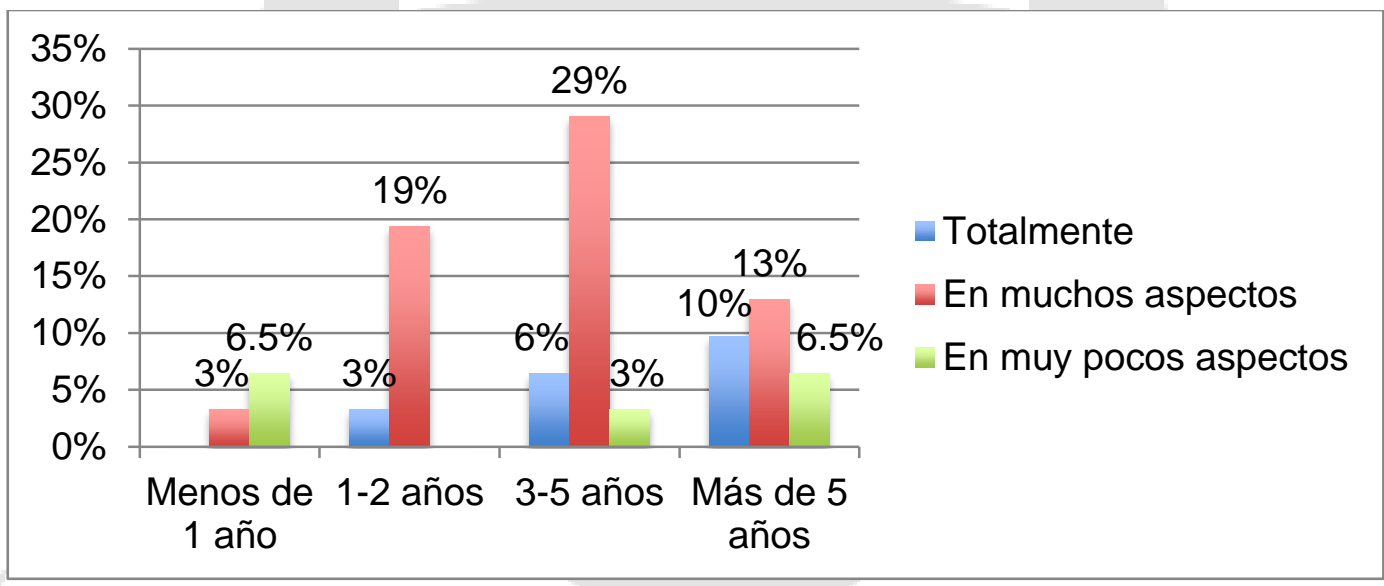

Fuente: Elaboración propia. 


\section{DISCUSIÓN}

La investigación ha demostrado que sí es posible gestionar el clima laboral en organismos estatales y reguladores. A través del caso Osiptel, se observa que esto es posible cuando los altos mandos y el equipo interno se interesan por y destinan esfuerzos para generar mejoras para el colaborador. Así, se rechaza la afirmación que las organizaciones públicas no gestionan el clima laboral; y se puede empezar a tomar a los organismos estatales y reguladores como objetos de estudio de la comunicación corporativa.

\subsection{Percepción de los colaboradores sobre el clima laboral en Osiptel.}

Se ha comprobado en la parte de resultados que, en términos generales, los colaboradores concuerdan que la gestión del clima laboral en Osiptel es satisfactoria. Sin embargo, la percepción sobre el mismo sigue siendo variada tanto entre gerencias como entre colaboradores de una misma gerencia. Algunas de ellas, como la Gerencia de Protección y Servicio al Usuario (GPSU), Procuraduría Pública (PP) y la Gerencia de Oficinas Desconcentradas (GOD), marcaron al menos una respuesta totalmente positiva en todos los aspectos de clima laboral tratados en la encuesta, mientras otras, como la Gerencia de TI, Comunicación y Estadística (GTICE) y la Gerencia de Fiscalización y Supervisión (GFS), no marcaron ninguna. Asimismo, dentro de GPSU, un $60 \%$ de colaboradores marcó la respuesta más positiva, mientras que otro $20 \%$ marcó la segunda más negativa en preguntas como fluidez de la comunicación o equidad en el trato, demostrando no solamente la existencia de microclimas por gerencia, sino que incluso en una misma área el concepto sobre el clima laboral ospitelino no es homogéneo. Aquí se comprueba la teoría de Richard Hall (1996), ya que los colaboradores perciben distintas características sobre el clima laboral que influyen en sus conductas y formas de pensar. También se comprueba el aspecto subjetivo de la teoría de Litwin y Stinger (1978) y se anula el aspecto compartido de Toro (2001), ya que a pesar que el regulador fomenta un mismo concepto y las mismas acciones para todos, la percepción de cada colaborador difiere respecto a la del resto de sus colegas, aunque sea en aspectos mínimos. Asimismo, estos resultados evidencian que no solo es necesario reforzar la gestión de clima laboral a nivel intergerencial, sino 
también a nivel individual, con el fin de homogeneizar el concepto en la institución y que éste sea más fácil de gestionar posteriormente.

La percepción del colaborador sobre el clima laboral también se ve influenciada por el tiempo que éste lleva en la institución; sin embargo, no se logró identificar un patrón que determine si a más o menos años de experiencia en Osiptel esta percepción era más o menos positiva debido a la amplia variedad de respuestas en las encuestas. A pesar de ello, los colaboradores con más de 2 años en la organización han experimentado el cambio y la estructuración del clima laboral en la institución desde la implementación del 'Modelo de Gestión de Recursos Humanos'; y fueron ellos quienes en las herramientas aplicadas mostraron un mayor conocimiento sobre el tema que aquellos que llevaban menos años en el regulador.

\subsection{Características de la gestión del clima laboral de Osiptel}

El clima laboral dentro de Osiptel depende de los valores y virtudes del equipo que lo integra. Como lo mencionó Roxana Sánchez, Doctora de Clima de la Gerencia de Oficinas Desconcentradas (GOD), desde hace más de 20 años, el regulador cuenta con un equipo de trabajo unido y solidario, el cual creó un ambiente agradable a través de gestos de agradecimiento, comunicación informal y abierta, trato horizontal por parte de los gerentes; y predisposición para ayudar al compañero. Estos componentes del clima laboral osiptelino son propios de cada persona y ellos los han transmitido a la organización en la vida laboral diaria. Por ello, si en una organización existe un equipo donde las virtudes de cada colaborador están alineadas o se complementan con las de los demás, ésta ya tiene tendencia a tener un clima laboral positivo sin importar al rubro al que pertenezca. Asimismo, se comprueba el aspecto permanente del clima laboral de acuerdo a la teoría de Forehand y Gilmer (1964). El clima laboral puede alterarse en una institución a través de acciones positivas o negativas, mas elementos como la fidelización del personal, el orgullo de pertenencia o los valores sirven de soporte para la organización en momentos de crisis y contribuyen a la permanencia de un clima laboral satisfactorio dentro de la misma.

El compromiso de los altos mandos también ha sido uno de los factores claves para que el clima laboral se logre solidificar en la institución. Poca hubiera sido la 
efectividad del 'Modelo de Gestión de Recursos Humanos' si el presidente, la gerente general y el cuerpo de gerentes no creían en él y no se interesaban por sus grupos de trabajo. Si bien la intensidad del compromiso varía de acuerdo a cada gerente, todos muestran la disposición de participar en las actividades de integración propuestas por GAF e incluso proponen ideas nuevas para que éstas sean más eficientes. La elaboración de un plan anual de clima laboral por gerencia afianza el compromiso de los jefes con sus respectivas áreas, viéndolo no solo como una ventaja sino como una meta a cumplir; a la vez que permite a GAF evaluar qué tan comprometido está cada uno de ellos con sus gerencias y afianzar o reforzar los aspectos necesarios. Si las cabezas de cualquier organización se interesan por sus públicos internos y se comprometen a hacer del centro laboral un buen lugar para trabajar, difícilmente se tendrá un clima laboral negativo en el mismo.

El reconocimiento del trabajo también juega un rol fundamental en el clima laboral de la organización. Esta filosofía crea un círculo vicioso donde el colaborador busca esforzarse en todos los aspectos de su vida porque sabe que lo van a reconocer por ello. El premio, a su vez, hace que la persona se sienta bien consigo misma y con la institución a la que pertenece; y va a seguir esforzándose y dando lo mejor de sí con el fin de obtener nuevamente un reconocimiento. Este es uno de los componentes de clima laboral según la teoría de Litwin y Stinger (1978) (ellos lo llaman "recompensa"). A pesar que el incentivo es emocional y no económico, este resulta suficiente para motivar al colaborador y logra contribuir con el clima laboral haciéndole sentir al osiptelino que es valioso.

\subsubsection{Características de la comunicación interna de Osiptel.}

El regulador ha trabajado correctamente la horizontalización de la comunicación interna y ha logrado reducir la distancia de poder entre gerentes y colaboradores a través de la implementación de política de puertas abiertas y la disposición de los superiores a escuchar e implementar ideas propuestas por sus equipos de trabajo. Este aspecto resulta importante considerando que una mayoría de instituciones estatales se caracteriza por un enfoque en la comunicación externa, una comunicación interna vertical y una distancia de poder alta. Estas características de la comunicación interna osiptelina representan una ventaja diferencial para el regulador 
dentro del sector estado y fortalecen tanto su identidad como su imagen. Sin embargo, debe crearse una comunicación más fluida entre gerencias y reforzar la comunicación en cascada desde el presidente al resto de colaboradores, para que así todos se sientan parte no solo de una gerencia sino de una misma institución y puedan estar al tanto de todo lo que acontece dentro de ella.

\subsubsection{Impacto de los 'Doctores de Clima'}

La implementación de los 'Doctores del Clima' ha sido fundamental para la mejora del clima laboral en Osiptel. Los doctores refuerzan el ambiente de trabajo en las gerencias al conocer a profundidad a cada colaborador y fomentar a su vez que ellos se conozcan entre sí. La transmisión de ideas de subordinado a jefe o viceversa permite a los altos mandos apreciar a su equipo de trabajo en un nivel profesional, mientras que la comunicación de problemas o quejas les presenta el ámbito emocional y mental del colaborador. Para los gerentes, subgerentes y jefes de área, conocer al colaborador en todas sus facetas es importante para poder encontrar la mejor manera de dirigirse a él, mientras que para los colaboradores es importante conocer a sus superiores para saber cómo tomar los mensajes que vienen de arriba y evitar llevar a nivel personal una mala reacción o llamada de atención por parte de ellos. Para lograr todo esto, es indispensable que los doctores sean empáticos y puedan manejar la presión de ser intermediarios entre colegas y superiores, al igual de entre colegas mismos. Por ello, la designación de los colaboradores más cercanos al gerente y a sus compañeros de área para dicho cargo ha permitido que éste se implemente exitosamente y muestre una vez más la importancia que se le da al clima laboral en la organización.

\subsection{Características de la implementación del Modelo de Gestión de Recursos}

\section{Humanos.}

\subsubsection{Importancia para la institución}

La aplicación del Modelo de Gestión de Recursos Humanos permitió unificar todos los elementos y acciones positivas de clima laboral que ya se tenían en un concepto más sólido; y aprovechar las virtudes y valores de cada colaborador para convertirlos en algo institucional. Cuando hay un buen clima laboral pero no está 
consolidado y se compone de acciones aisladas, el elaborar un plan es una alternativa eficiente para conceptualizarlo y hacer de él una pieza fundamental para la organización.

\subsubsection{Conocimiento y difusión.}

Osiptel tiene un clima laboral positivo a pesar que no todos los colaboradores conocen a profundidad el 'Modelo de Gestión de Recursos Humanos'. La falta de difusión del modelo se siente en los altos mandos y, especialmente, en los 'Doctores del Clima', quienes ven su interés por seguir contribuyendo con la organización limitado al no estar informados sobre qué acontece en las otras gerencias y qué otros aspectos, aparte de los de su propia competencia, trabaja este plan. Si bien es importante que todos los colaboradores sepan que existe un modelo, no es necesario que lo conozcan en todos sus aspectos ya que se arruinaría el factor sorpresa. Sin embargo, es necesario mantener el interés de tanto los altos mandos como de los 'Doctores del Clima' en continuar mejorando el clima laboral dentro de sus gerencias y, sobretodo, a nivel institucional, para lo cual una mayor difusión del plan contribuiría al darles más aspectos en qué trabajar y ampliar su conocimiento y participación sobre lo que se hace actualmente y se puede hacer en el futuro.

\subsection{Impacto de la gestión del clima laboral en la identidad e imagen corporativa de} Osiptel.

La gestión del clima laboral en Osiptel tiene un impacto primordial en todos sus públicos, especialmente dentro de un sector que es conocido por sus propios miembros por no tener ambientes de trabajo agradables. En el ámbito interno y, siguiendo la teoría de Joan Costa (2009), la gestión del clima laboral en sí misma compone parte de la identidad corporativa de Osiptel, ya que es uno de los factores fundamentales de la organización (ADN), no suele darse en otros organismos del mismo sector (singularidad), le brinda al colaborador un espacio agradable para que pueda aprovechar al máximo sus habilidades y logre un desempeño laboral eficiente (capacidad) y crea un sentido de orgullo y fidelización que permite la retención del talento y que la organización crezca con un mismo equipo (potencial desarrollo futuro). La identidad corporativa de Osiptel también es reforzada a través de las actividades de 
integración, ya que éstas fomentan y refuerzan los valores institucionales, componentes también del ADN de la organización. Aquí también resalta el factor diferencial de clima laboral señalado por Anzola (2003), ya que la gestión del mismo en Osiptel logra diferenciarlo de otros organismos reguladores e instituciones estatales.

En el ámbito externo, la imagen corporativa de Osiptel también es fortalecida gracias a la gestión del clima laboral, especialmente por los públicos más cercanos a los miembros del regulador. En diversas ocasiones, cónyuges, hijos u otros familiares de los colaboradores participan directamente de las actividades de integración del regulador, compartiendo ellos también lo que se vive en la institución y llevándose una impresión positiva de la misma. Asimismo, la solidaridad mostrada ante hechos o eventos importantes para la vida personal de cada colaborador, como matrimonios, nacimientos de bebés o pérdidas familiares, también causa un impacto positivo en el círculo social del colaborador, sintiendo el apoyo brindado por una institución a la cual no pertenecen directamente y creando una imagen positiva de Osiptel. Por otro lado, otros grupos de interés también pueden obtener una imagen positiva del regulador, ya que al estar los colaboradores fidelizados con sus institución, tendrán un desempeño más eficiente y un mejor estado anímico, lo cual hará la interacción con otros grupos de interés más amena y positiva y les permitirá a ellos llevarse una imagen favorable del organismo regulador.

\subsection{Recomendaciones}

Según los resultados recogidos y el contenido analizado, se proponen las siguientes recomendaciones para la mejora de la gestión del clima laboral en Osiptel:

a) Trabajar el clima laboral como concepto con cada colaborador: Como se mencionó anteriormente, por más que una gerencia o, inclusive, la institución en general tenga un clima laboral positivo, no todos los colaboradores van a tener un mismo concepto de lo que se vive en ella. Por ello, es necesario realizar acciones que permitan identificar lo que cada uno de los colaboradores conoce y entiende por clima laboral y buscar mejorar su percepción del mismo a nivel personal. Los 'Doctores del Clima' pueden encargarse de esto, ya que son ellos 
los que conocen a profundidad a cada colaborador de sus respectivas gerencias y pueden encontrar la mejor manera de dirigirse a ellos.

b) Establecer la comunicación interna como un factor importante para la gestión del clima laboral: La horizontalidad de la comunicación ha sido muy bien trabajada desde la fundación de la organización. Sin embargo, debe trabajarse la interacción entre gerencias y mejorar la fluidez de la comunicación, creando una mayor cantidad de canales y buscando identificar los tonos adecuados de mensajes de acuerdo a cada colaborador con el fin de reforzar la gestión del clima laboral. Para ello, se sugiere realizar un diagnóstico comunicacional para determinar las fallas y complementarlo con un plan de comunicación que pueda contrarrestarlas. También se recomienda que GAF elabore de contenidos internos sin supervisión de otras gerencias, con el fin de evitar tensiones entre ellas y poder crear conceptos y mensajes con mayor libertad, siempre respetando los estándares institucionales establecidos en el Manual de Identidad osiptelina.

c) Reforzar la comunicación del Modelo de Gestión de Recursos Humanos: Se recomienda realizar dos tipos de difusión para el Modelo de Gestión. La primera para todos los colaboradores, donde se recuerde la existencia del modelo y se comuniquen los aspectos importantes como cultura corporativa, identidad corporativa, valores institucionales y aspectos generales del clima laboral sin llegar a quitar el factor sorpresa de las actividades de integración. La segunda solo para gerentes y 'Doctores del Clima', donde se comunique el plan más a profundidad (si es posible, en su totalidad), con el fin de reforzar el compromiso de ambos, informarles de todo lo que sucede en la institución y que puedan trabajar conjuntamente en nuevos conceptos, ideas y actividades.

d) Aumentar la interacción y retroalimentación entre gerentes, 'Doctores de Clima' y GAF: Un mayor número de reuniones entre los 'Doctores del Clima' y GAF permitirá a ambos informarse más de lo que sucede en cada gerencia y crear nuevas actividades en un plazo más corto que subsanen inconvenientes o refuercen actitudes positivas. Asimismo, reuniones periódicas con todos los gerentes donde ellos puedan discutir con GAF el clima laboral de sus gerencias permitirá a la gerencia encargada tener un diagnóstico de primera mano sobre sus propias percepciones del clima en sus respectivas áreas; y fomentará la interacción y compartición de ideas entre gerencias. 
e) Diagnosticar y erradicar los microclimas por gerencia: Una vez que las recomendaciones previas hayan sido realizadas, se podrá diagnosticar el porqué de la percepción de microclimas dentro de la organización por parte de algunos colaboradores e implementar acciones que permitan ver a todos los osiptelinos por igual al clima laboral como parte de toda la organización y no solo de determinadas gerencias. De esta manera, se homogeneizará la percepción sobre clima laboral dentro de la organización y se contrarrestarán las sensaciones negativas entre gerencias, creando un clima laboral totalmente institucional.

Para erradicar la percepción de microclimas por gerencia, se propone el siguiente plan:

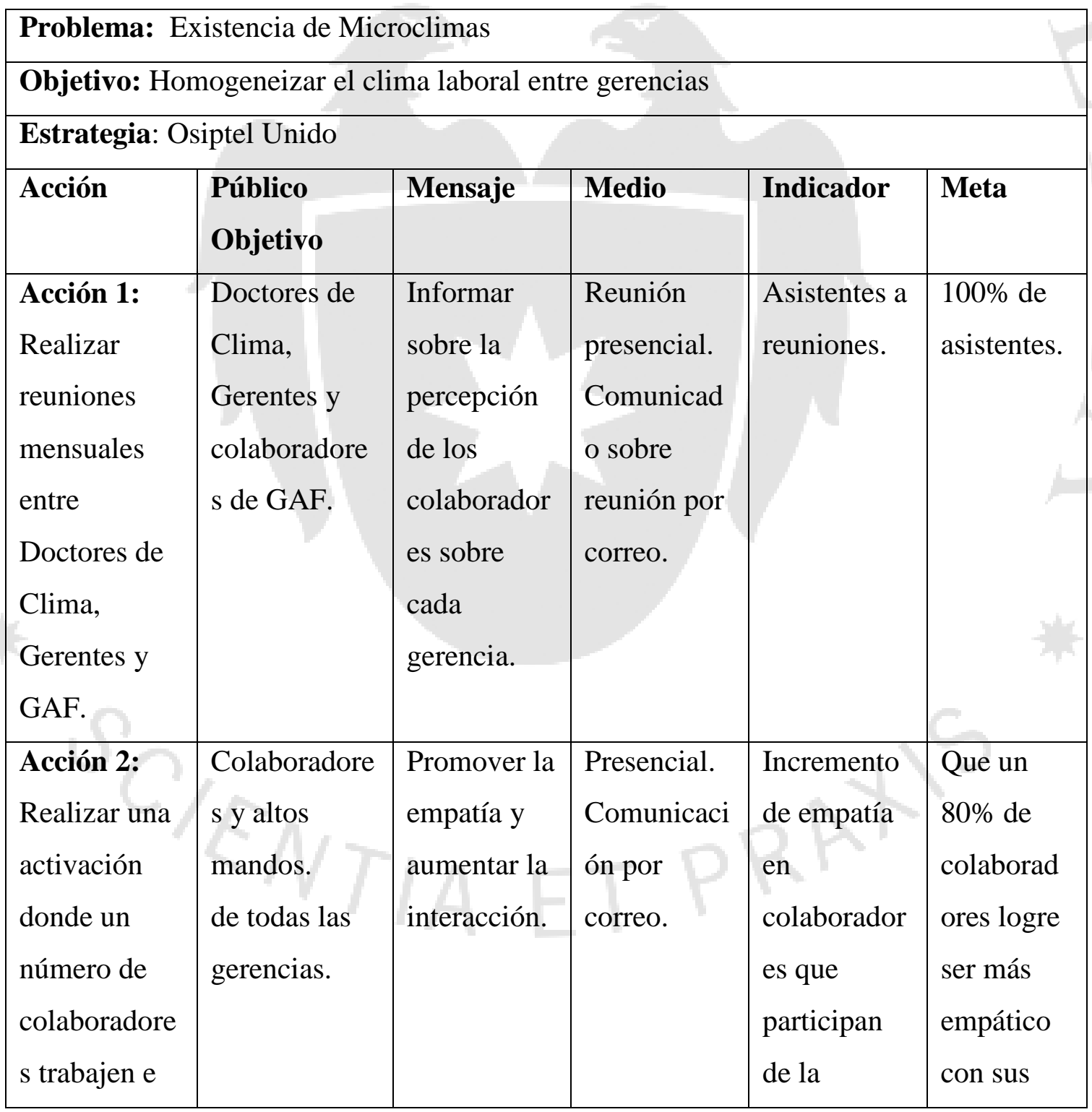




\begin{tabular}{|c|c|c|c|c|c|}
\hline $\begin{array}{l}\text { interactúe } \\
\text { por un día en } \\
\text { otra gerencia }\end{array}$ & & & & activación. & $\begin{array}{l}\text { compañer } \\
\text { os. }\end{array}$ \\
\hline $\begin{array}{l}\text { Acción 3: } \\
\text { Organizar } \\
\text { almuerzos } \\
\text { de } \\
\text { integración } \\
\text { entre dos } \\
\text { gerencias } \\
\text { elegidas al } \\
\text { azar. }\end{array}$ & $\begin{array}{l}\text { Colaboradore } \\
\text { s de todas las } \\
\text { gerencias. }\end{array}$ & $\begin{array}{l}\text { Conocerse } \\
\text { más entre } \\
\text { gerencias e } \\
\text { incrementar } \\
\text { la } \\
\text { interacción. }\end{array}$ & $\begin{array}{l}\text { Presencial. } \\
\text { Comunicaci } \\
\text { ón por } \\
\text { correo. }\end{array}$ & $\begin{array}{l}\text { Interacción } \\
\text { entre } \\
\text { colaborador } \\
\text { es de } \\
\text { distintas } \\
\text { gerencias } \\
\text { durante el } \\
\text { almuerzo }\end{array}$ & $\begin{array}{l}\text { Que un } \\
90 \% \text { de } \\
\text { asistentes } \\
\text { logre } \\
\text { interactuar } \\
\text { con un } \\
\text { colaborad } \\
\text { or de la } \\
\text { otra } \\
\text { gerencia } \\
\text { durante el } \\
\text { almuerzo }\end{array}$ \\
\hline
\end{tabular}

Para reforzar la comunicación interna, se plantea el siguiente plan:

Problema: Comunicación interna como aspecto a reforzar.

Objetivo: Fortalecer la comunicación interna en Osiptel.

Estrategia: Todos informados.

\begin{tabular}{|c|c|c|c|c|c|}
\hline Acción & $\begin{array}{l}\text { Público } \\
\text { Objetivo }\end{array}$ & Mensaje & Medio & Indicador & Meta \\
\hline $\begin{array}{l}\text { Acción1: } \\
\text { Realizar } \\
\text { reuniones } \\
\text { entre el } \\
\text { gerente de } \\
\text { área y los } \\
\text { colaboradore } \\
\text { s donde se }\end{array}$ & $\begin{array}{l}\text { Gerentes y } \\
\text { colaborador } \\
\text { es de cada } \\
\text { gerencia. }\end{array}$ & $\begin{array}{l}\text { Todo el } \\
\text { equipo } \\
\text { merece } \\
\text { estar } \\
\text { informado } \\
\text { de lo que } \\
\text { sucede en } \\
\text { Osiptel. }\end{array}$ & $\begin{array}{l}\text { Reunión } \\
\text { presencial. }\end{array}$ & $\begin{array}{l}\text { Información } \\
\text { exacta } \\
\text { brindada por } \\
\text { el gerente. }\end{array}$ & $\begin{array}{l}\text { Que un } \\
90 \% \text { de } \\
\text { colaborador } \\
\text { es de cada } \\
\text { gerencia } \\
\text { esté } \\
\text { debidament } \\
\text { e informado }\end{array}$ \\
\hline
\end{tabular}




\begin{tabular}{|c|c|c|c|c|c|}
\hline $\begin{array}{l}\text { informe de } \\
\text { lo } \\
\text { conversado } \\
\text { en el comité } \\
\text { de gerentes. }\end{array}$ & & & & & $\begin{array}{l}\text { de lo } \\
\text { conversado } \\
\text { en el comité } \\
\text { de gerentes. }\end{array}$ \\
\hline $\begin{array}{l}\text { Acción 2: } \\
\text { Retroaliment } \\
\text { ar las } \\
\text { actividades } \\
\text { de } \\
\text { integración } \\
\text { de GAF }\end{array}$ & $\begin{array}{l}\text { Colaborador } \\
\text { es de todas } \\
\text { las } \\
\text { gerencias. }\end{array}$ & $\begin{array}{l}\text { Conocer la } \\
\text { opinión de } \\
\text { los } \\
\text { colaborador } \\
\text { es sobre los } \\
\text { esfuerzos de } \\
\text { GAF. }\end{array}$ & $\begin{array}{l}\text { Encuesta } \\
\text { por correo } \\
\text { electrónico. }\end{array}$ & $\begin{array}{l}\text { Opiniones } \\
\text { recogidas de } \\
\text { los } \\
\text { colaborador } \\
\text { es. }\end{array}$ & $\begin{array}{l}\text { Recoger un } \\
90 \% \text { de } \\
\text { opiniones } \\
\text { de los } \\
\text { colaborador } \\
\text { es }\end{array}$ \\
\hline $\begin{array}{l}\text { Acción 3: } \\
\text { Realizar una } \\
\text { charla } \\
\text { informativa } \\
\text { sobre la } \\
\text { importancia } \\
\text { de compartir } \\
\text { información } \\
\text { entre } \\
\text { gerencias. }\end{array}$ & $\begin{array}{l}\text { Colaborador } \\
\text { es y altos } \\
\text { mandos. }\end{array}$ & $\begin{array}{l}\text { El } \\
\text { compartir } \\
\text { información } \\
\text { facilita el } \\
\text { trabajo y } \\
\text { vuelve el } \\
\text { ambiente } \\
\text { más } \\
\text { agradable. }\end{array}$ & $\begin{array}{l}\text { Presencial. } \\
\text { Comunicaci } \\
\text { ón por } \\
\text { correo. }\end{array}$ & $\begin{array}{l}\text { Incremento } \\
\text { de empatía } \\
\text { en } \\
\text { colaborador } \\
\text { es que } \\
\text { participan de } \\
\text { la activación }\end{array}$ & \\
\hline
\end{tabular}

\subsection{Conclusiones}

El presente artículo ha demostrado que los organismos estatales y reguladores sí tienen clima laboral y trabajan aspectos de la comunicación corporativa de manera eficiente, por lo cual no se les debe excluir de estudios de esta índole por ningún motivo. Cada organización tiene características comunicacionales propias y todas 
merecen ser estudiadas de una misma manera para expandir adecuadamente la rama de la comunicación corporativa.

Asimismo, se concluye que el equipo humano es indispensable para que una organización logre tener un clima laboral positivo, independientemente del rubro al que pertenezca. El compromiso por parte de los altos mandos también es trascendental para que esto se logre, especialmente cuando se busca implementar un plan de clima laboral dentro de la organización.

Tener una comunicación horizontal no necesariamente significa que ésta vaya a ser eficiente. La comunicación interna tiene varios aspectos a considerar (fluidez, canales, eficiencia, tono), los cuales siempre deben tomarse en cuenta al momento de evaluársele.

Finalmente, el desarrollar un plan de clima laboral dentro de una organización resulta efectivo para la consolidación del mismo, pero debe difundirse y comunicarse adecuadamente para trabajarse conjuntamente y fortalecer el interés y compromiso de todas las partes involucradas. 


\section{REFERENCIAS}

1. Forehand G.A., Gilmer B. (1964). Environmental Variation in studies of organizational behavior. Psychological Bulletin

2. Litwin, G. \& Stinger H. (1978). Organizational Climate. Nueva York: Simon\&Schuster.

3. Hall, R. (1996). Organizaciones, Estructura, Procesos y Resultados. 2da Edición. México DF: Printice Hall.

4. Plan de Mejora de Clima 2016 - realizado por la Gerencia de Administración y Finanzas de Osiptel (2016).

5. Plan de Bienestar 2016 - realizado por la Gerencia de Administración y Finanzas de Osiptel (2016).

6. Respuestas cultura auditoría 2016 parte 1 - realizado por Great Place to Work (2016).

7. Sistema de RR.GHH - elaborado por la Autoridad Nacional del Servicio Civil (2013).

8. Hofstede, G. (2005) Cultures and organizations: software of the mind. ISBN0-07-14395.

9. Costa, J. (2009). El DirCom hoy: Dirección y Gestión de la comunicación en la nueva economía. España: Costa Punto Com.

10. Costa, J. (1999). La comunicación en acción : informe sobre la nueva cultura de la gestión. España: Paidos Ibérica.

11. Berceruelo, B. (2011). Comunicación interna en la empresa: claves y desafíos. España: Wolters Kluwer.

12. Ind, N. (1990). La imagen corporativa: Estrategias para desarrollar programas de identidad eficaces. España: Díaz de Santos.

13. Elías, J \& Mascaray, J. (2000). Más allá de la comunicación interna: La intracomunicación. España: Ediciones Gestión 2000.

14. Toro, F. (2001). Clima Organizacional. Perfil de empresas colombianas. Medellín: Cincel.

15. Anzola, O. (2003). Una mirada de la cultura corporativa. Colombia: Externado de Colombia. 


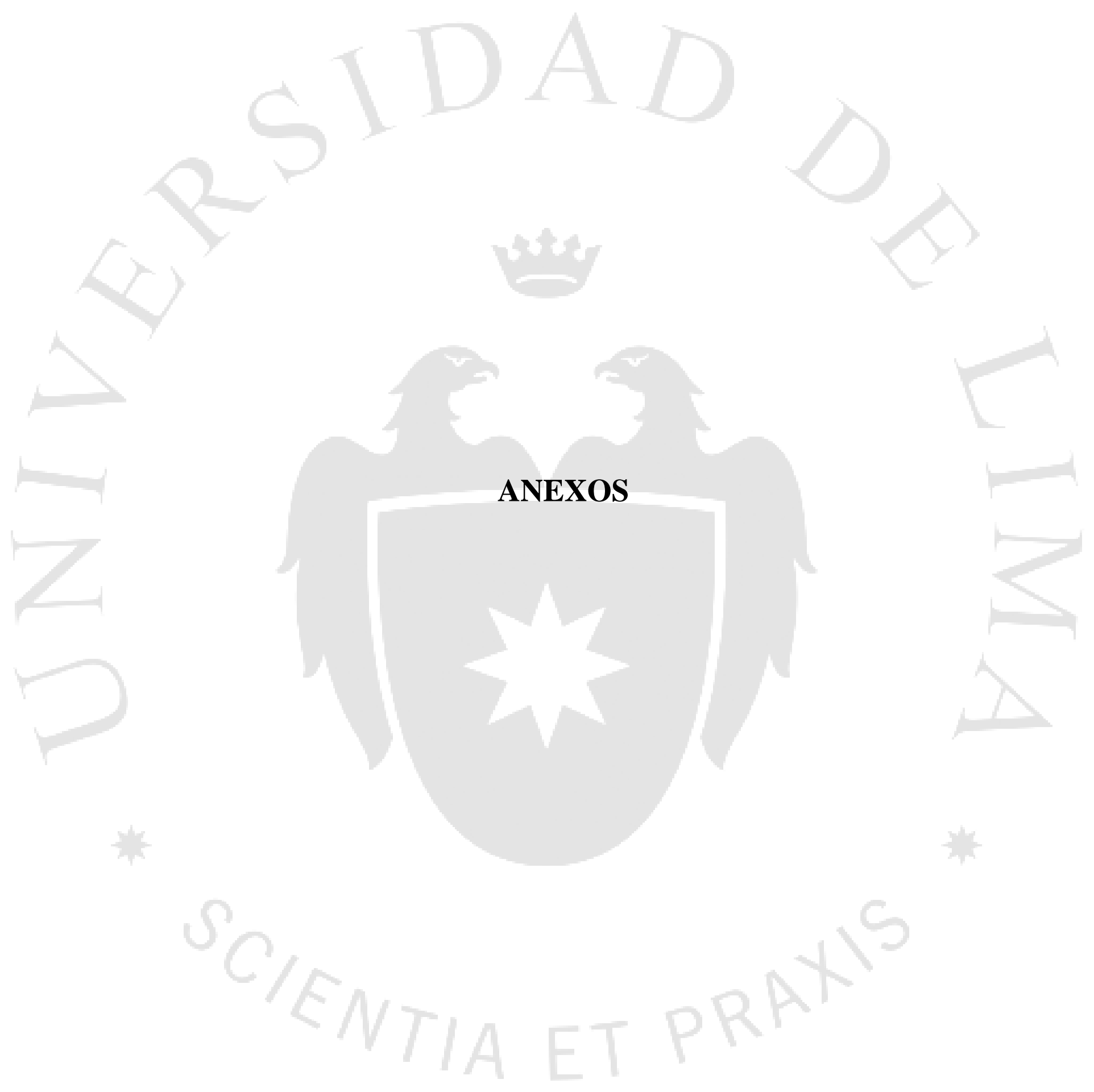

27 


\section{ANEXO 1: Cuestionario de encuesta de Clima Laboral realizada a colaboradores de Osiptel}

\section{Encuesta Clima Laboral - Osiptel}

1. ¿A qué gerencia o área pertenece?
a) Presidencia/Gerencia General.
b) Procuraduría Pública.
c) Órgano de Control Institucional.
d) Gerencia de Administración y Finanzas.
e) Gerencia de Asesoría Legal.
f) Gerencia de TI, Estadística y Comunicaciones.
g) Gerencia de Planeamiento y Presupuesto.
h) Gerencia de Comunicación Corporativa.
i) Gerencia de Políticas Regulatorias y Competencia.
j) Gerencia de Fiscalización y Supervisión.
k) Gerencia de Protección al Usuario
1) Gerencia de Oficinas Desconcentradas.
m) Otra (especificar)

2. ¿Cuál es su cargo actual?

3. ¿Cuánto tiempo lleva trabajando en la institución?
a) Menos de un año
b) 1-2 años.
c) 3-5 años.
d) Más de 5 años.

4. ¿Cuál fue su modalidad de contrato? 

a) Planilla/CAP.
b) CAS.
c) Temporal
d) Suplencia.

5. ¿Considera usted que su trabajo es valorado por sus superiores y compañeros?
a) Siempre
b) Casi siempre.
c) En ocasiones.
d) Casi nunca.
e) Nunca.

6. ¿Considera usted que sus compañeros y superiores saben escucharse los unos a los otros?
a) Siempre
b) Casi siempre.
c) En ocasiones.
d) Casi nunca.
e) Nunca.

7. ¿Considera usted que existe equidad en el trato hacia todos los colaboradores por parte de los superiores?
a) Siempre
b) Casi siempre.
c) En ocasiones.
d) Casi nunca.
e) Nunca.

8. Si se comete un error en el trabajo, ¿siente que tanto sus compañeros como sus superiores lo manejan adecuadamente? 

a) Siempre
b) Casi siempre.
c) En ocasiones.
d) Casi nunca.
e) Nunca.

9. Si se logra un triunfo laboral importante, ¿siente usted que tanto sus compañeros como sus superiores lo reconocen adecuadamente?
a) Siempre.
b) Casi siempre.
c) En ocasiones.
d) Casi Nunca.
e) Nunca.

10. ¿Siente usted que existe una comunicación fluida y adecuada entre todos los colaboradores de la institución? (incluyendo diferentes áreas).
a) Siempre
b) Casi siempre.
c) En ocasiones.
d) Casi nunca.
e) Nunca.

11. ¿Siente usted confianza como para acercarse con problemas personales a sus compañeros o superiores?
a) Siempre
b) Casi siempre.
c) En ocasiones.
d) Casi nunca.
e) Nunca. 
12. ¿Asiste usted a las actividades de integración que realiza el regulador?
a) Siempre.
b) Casi siempre.
c) En ocasiones.
d) Casi nunca.
e) Nunca.

13. ¿Conoce usted sobre la existencia de un modelo de gestión de recursos humanos en Osiptel?
a) Sí.
b) No. (si marcó esta opción, dar por concluida la encuesta)

14. ¿Cuánto conoce usted sobre dicho modelo?
a) Todo.
b) Algunos aspectos.
c) Muy poco.
d) Nada.

15. ¿Cuánto conoce usted sobre la cultura organizacional que tiene Osiptel?
a) Todo.
b) Algo.
c) Muy poco.
d) Nada.

16. ¿Cuánto conoce usted sobre los seis valores en los que se basa el clima laboral de Osiptel?
a) Conoce todos los valores.
b) Conoce algunos valores.
c) Ha escuchado que existen valores, pero no los conoce. 
d) Nada.

17. ¿Cuánto cree usted que lo propuesto en el modelo concuerda con la realidad de la institución?

a) Totalmente.

b) En muchos aspectos.

c) En muy pocos aspectos.

d) En nada.

e) No conozco el modelo.

18. ¿Considera usted que este modelo ha sido suficientemente difundido y comunicado por el área correspondiente?

a) Sí, totalmente.

b) Sí, en su mayoría.

c) Sí, pero en pocos aspectos.

d) No, en absoluto. 
ANEXO 2: Resultados de encuesta de clima laboral realizada a colaboradores de Osiptel

Anexo 2.1: Resultados por frecuencia 
Gráfico 1: ¿A qué gerencia o área pertenece?

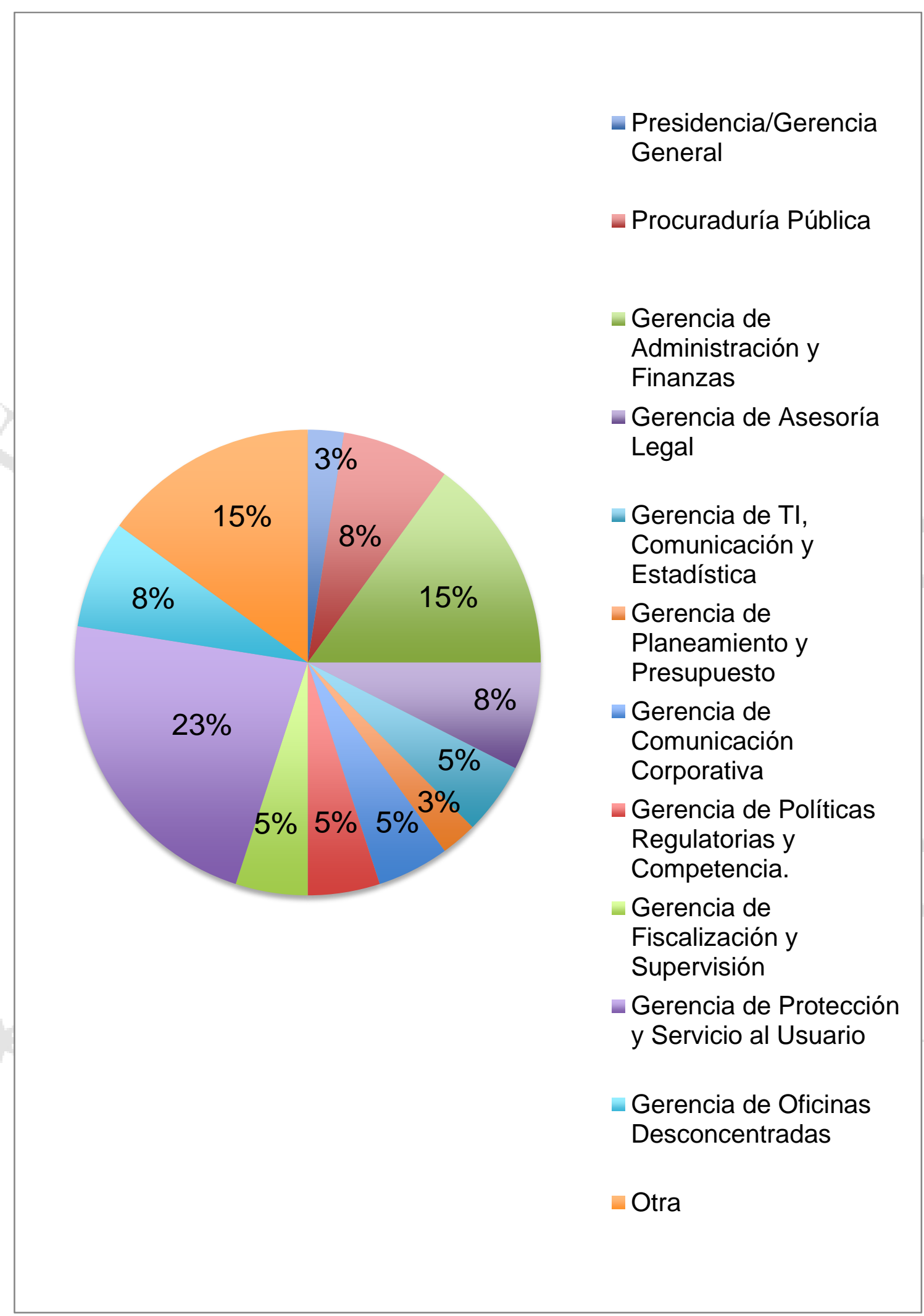

Fuente: Elaboración propia. 
Gráfico 2: ¿Cuánto tiempo lleva trabajando en la institución?

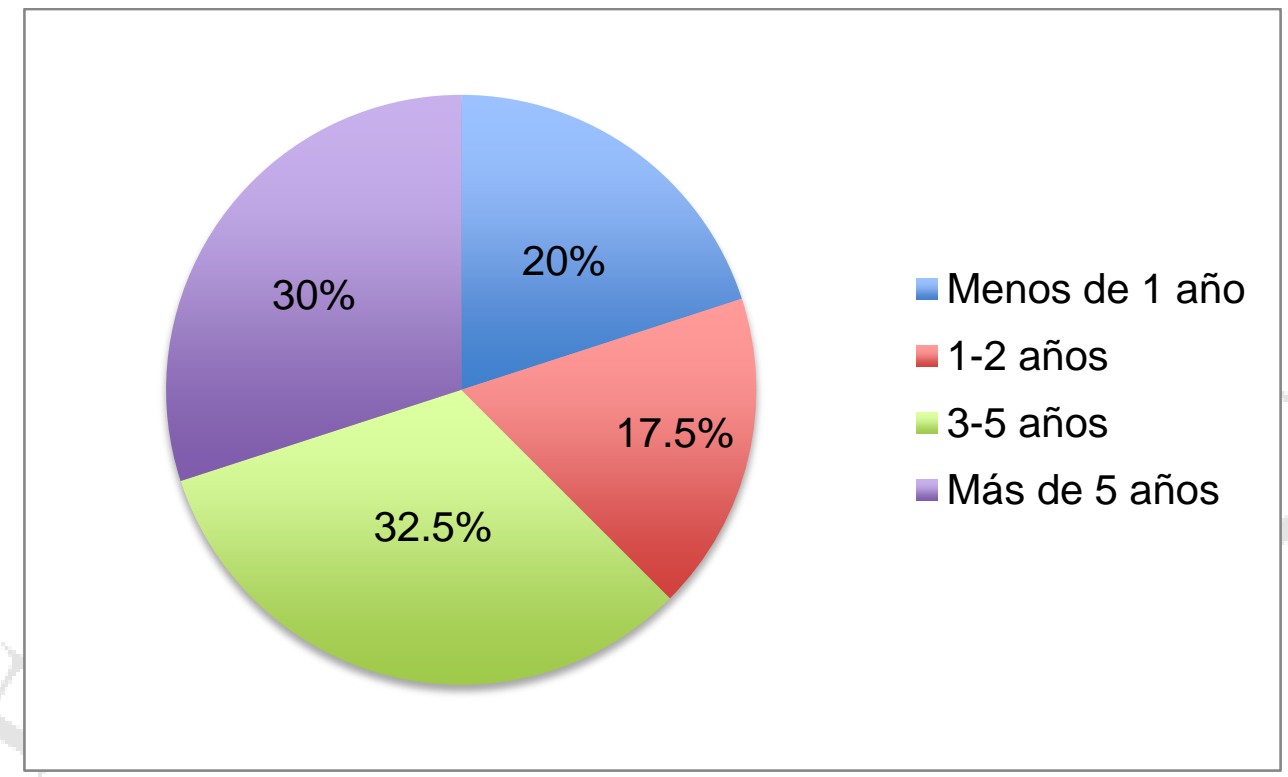

Fuente: Elaboración propia.

Gráfico 3: ¿Cuál fue su modalidad de contrato?

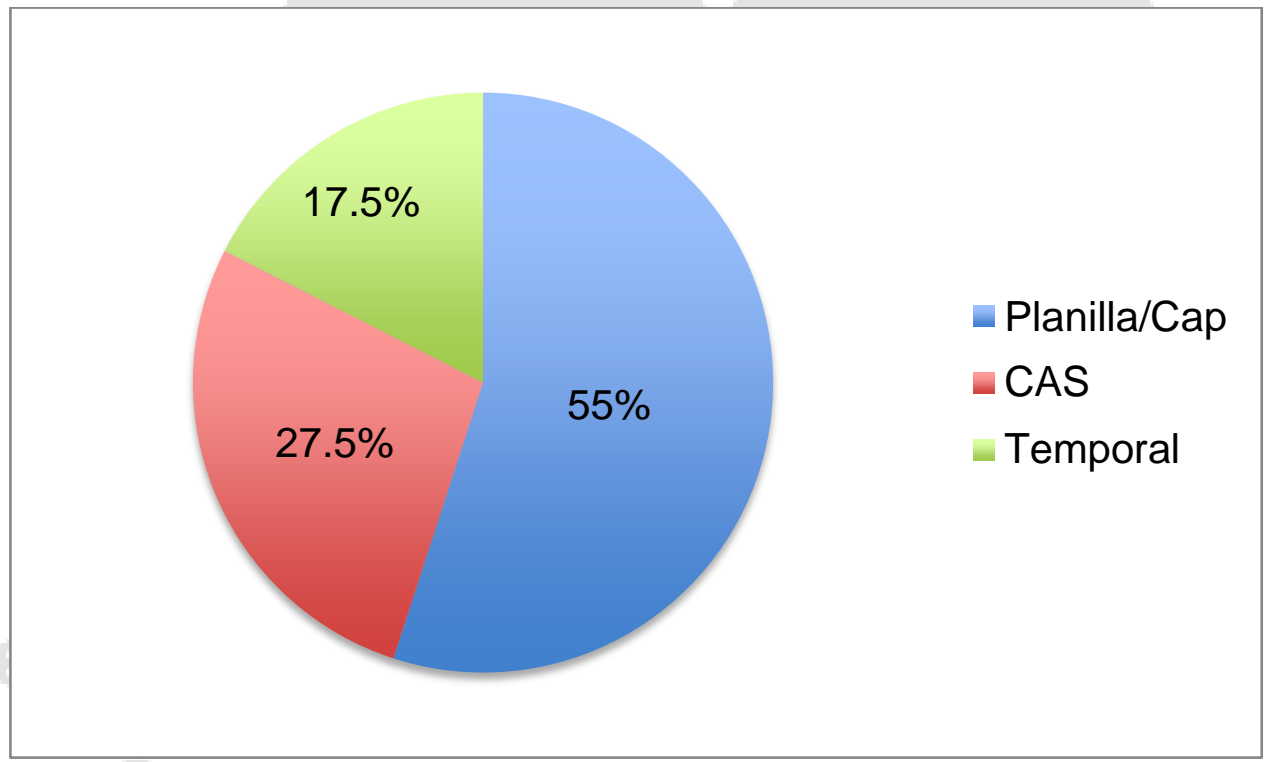

Fuente: Elaboración propia. 
Gráfico 4: ¿Considera usted que su trabajo es valorado por sus compañeros y superiores?

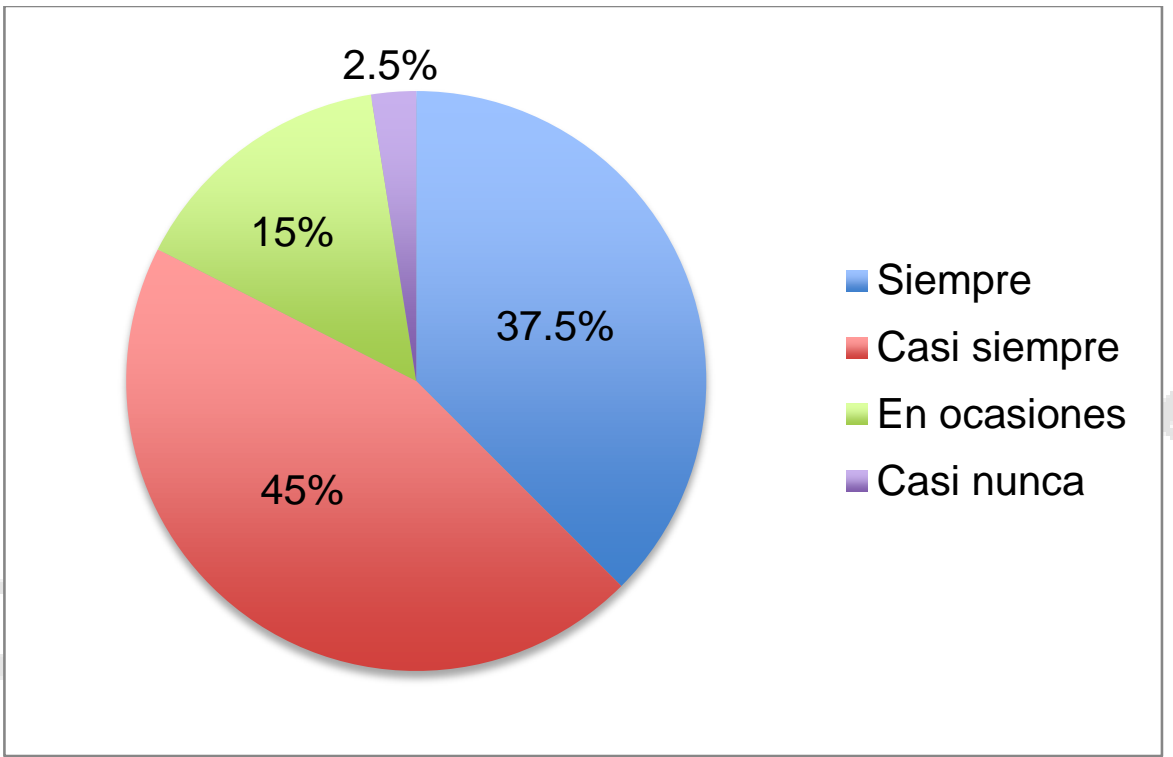

Fuente: Elaboración propia.

Gráfico 5: ¿Considera usted que sus compañeros y superiores saben escucharse los unos a los otros?

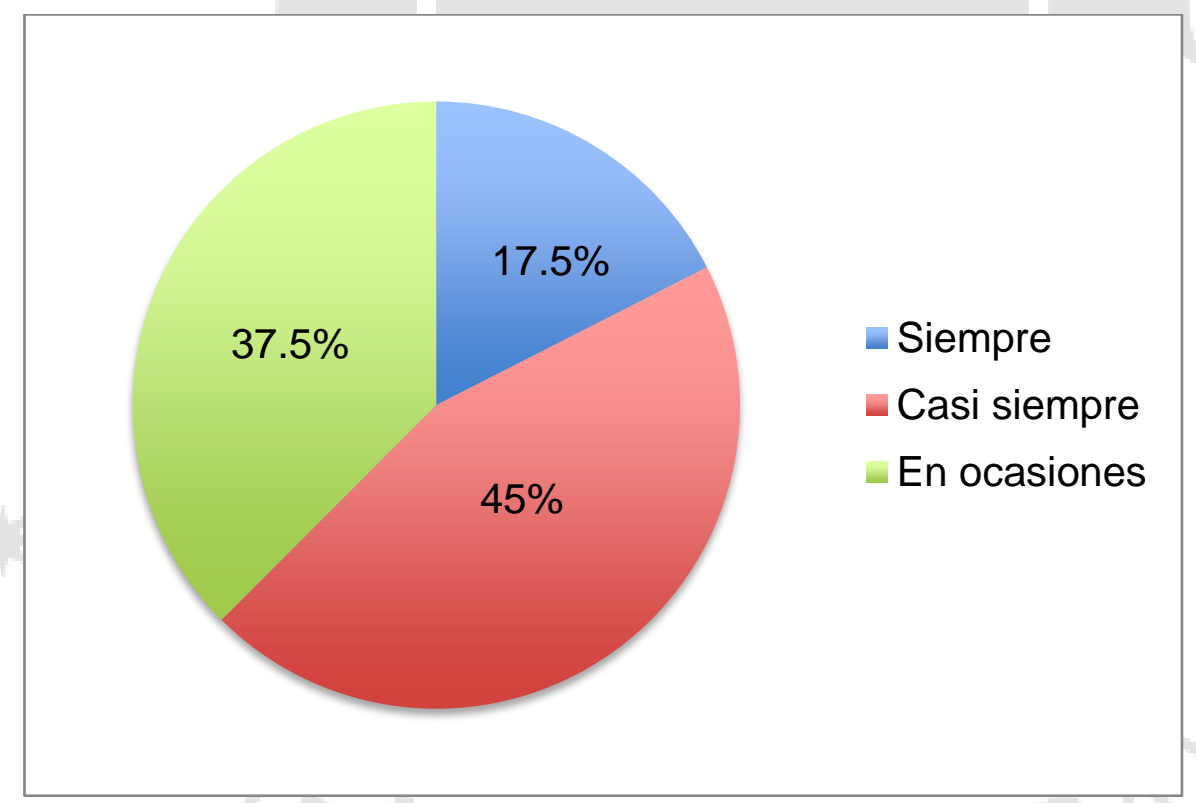

Fuente: Elaboración propia. 
Gráfico 6: ¿Considera usted que existe equidad en el trato hacia todos los colaboradores por parte de los superiores?

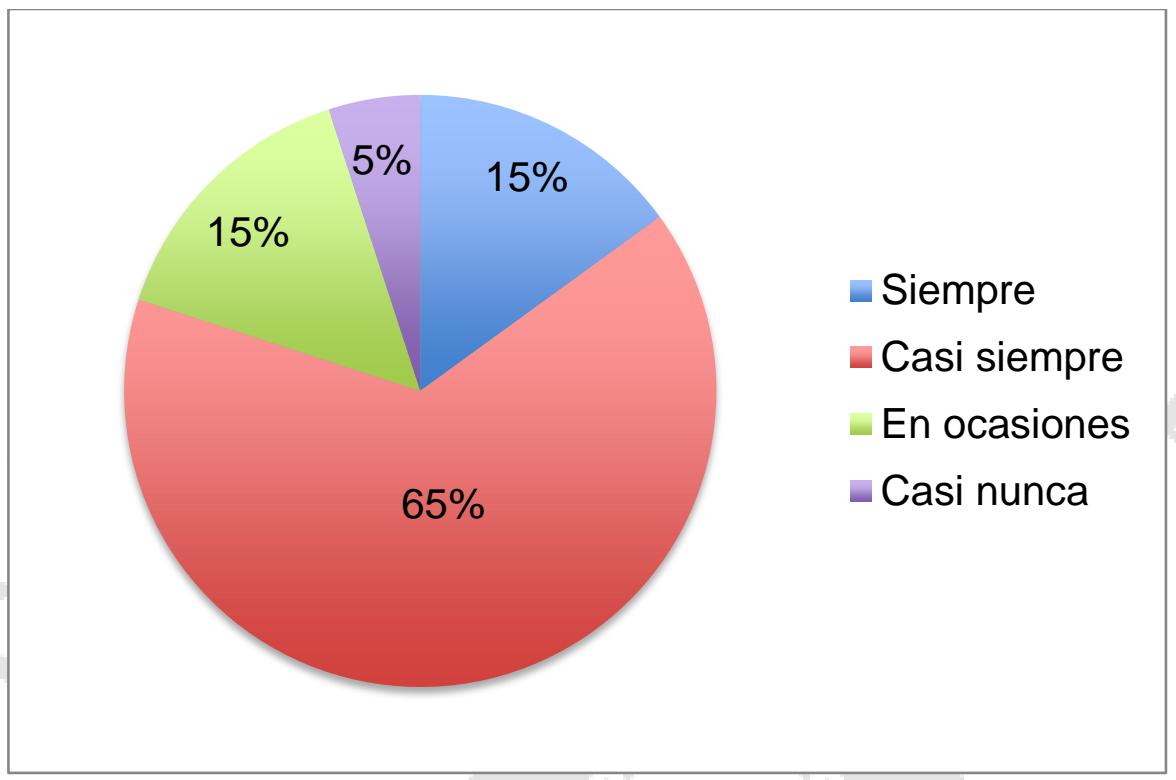

Fuente: Elaboración propia.

Gráfico 7: Si se comete un error en el trabajo, ¿siente que tanto sus compañeros como sus superiores lo manejan adecuadamente?

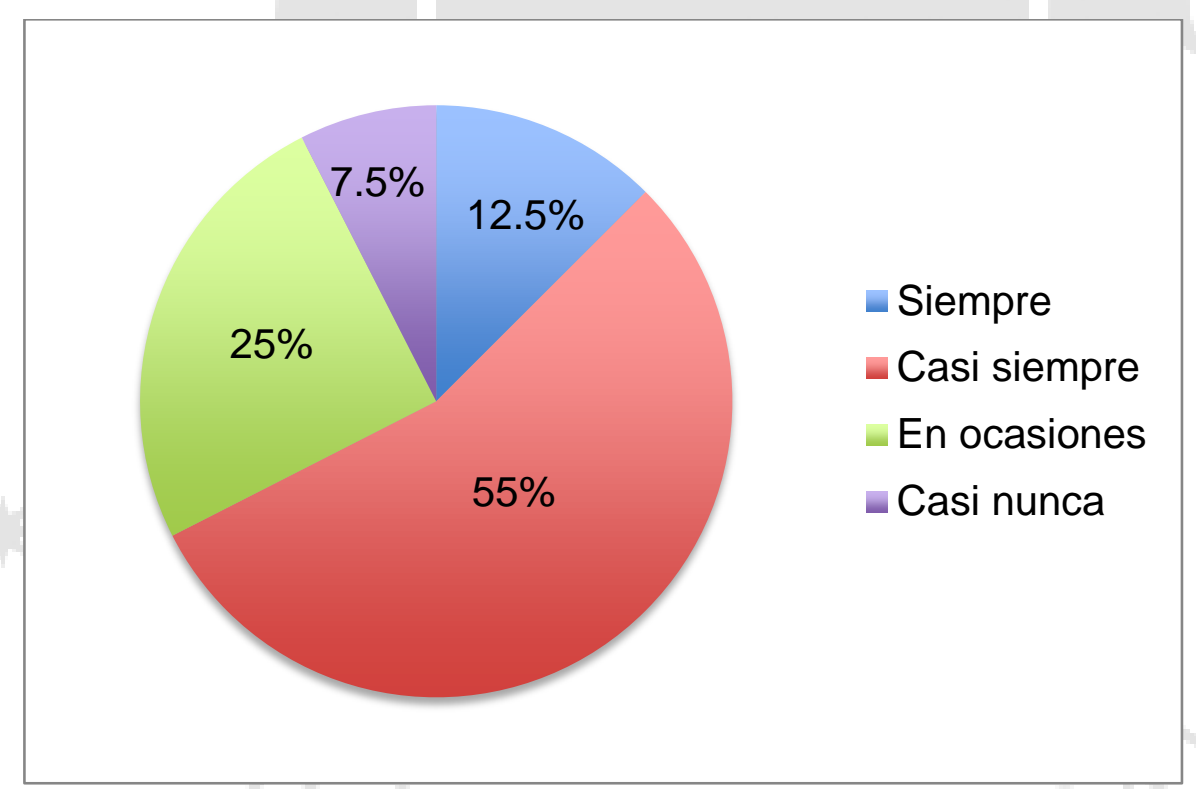

Fuente: Elaboración propia. 
Gráfico 8: Si se logra un triunfo laboral importante, ¿siente usted que tanto sus compañeros como sus superiores lo reconocen adecuadamente?

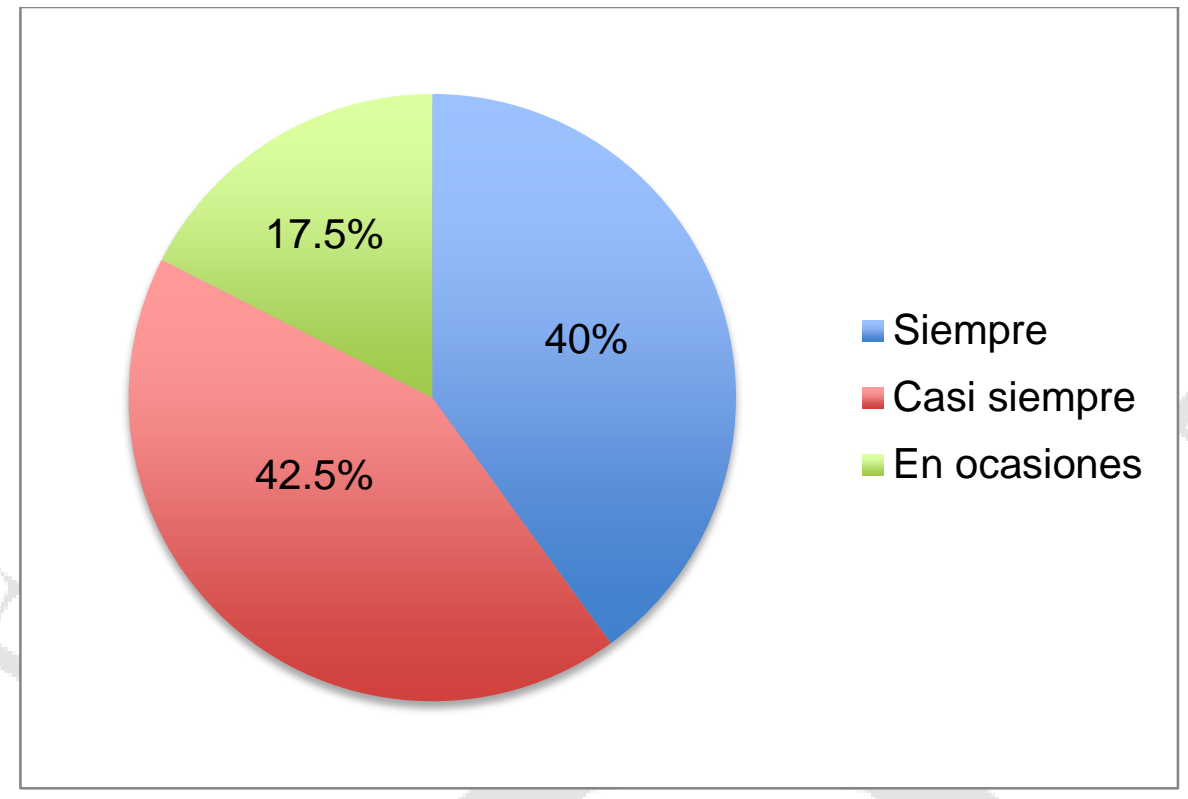

Fuente: Elaboración propia.

Gráfico 9: ¿Siente usted que existe una comunicación fluida y adecuada entre todos los colaboradores de la institución? (incluyendo diferentes áreas).

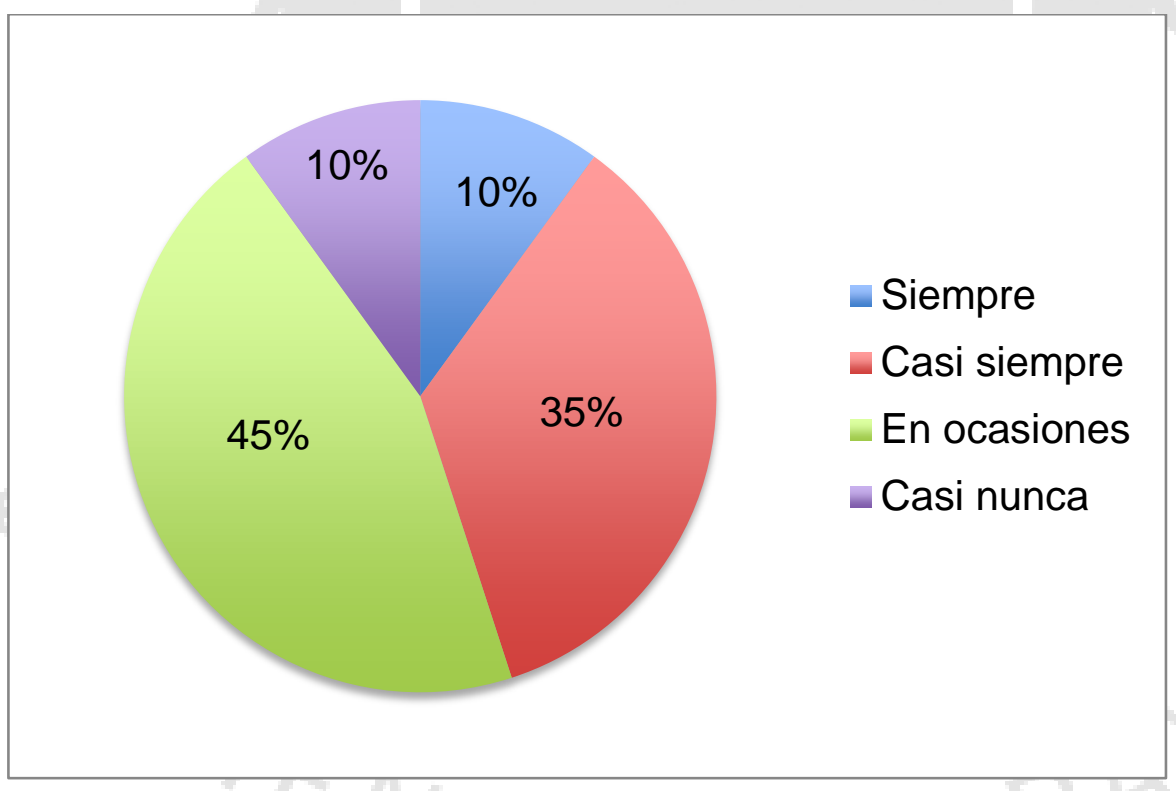

Fuente: Elaboración propia. 
Gráfico 10: ¿Siente usted confianza como para acercarse con problemas personales a sus compañeros o superiores?

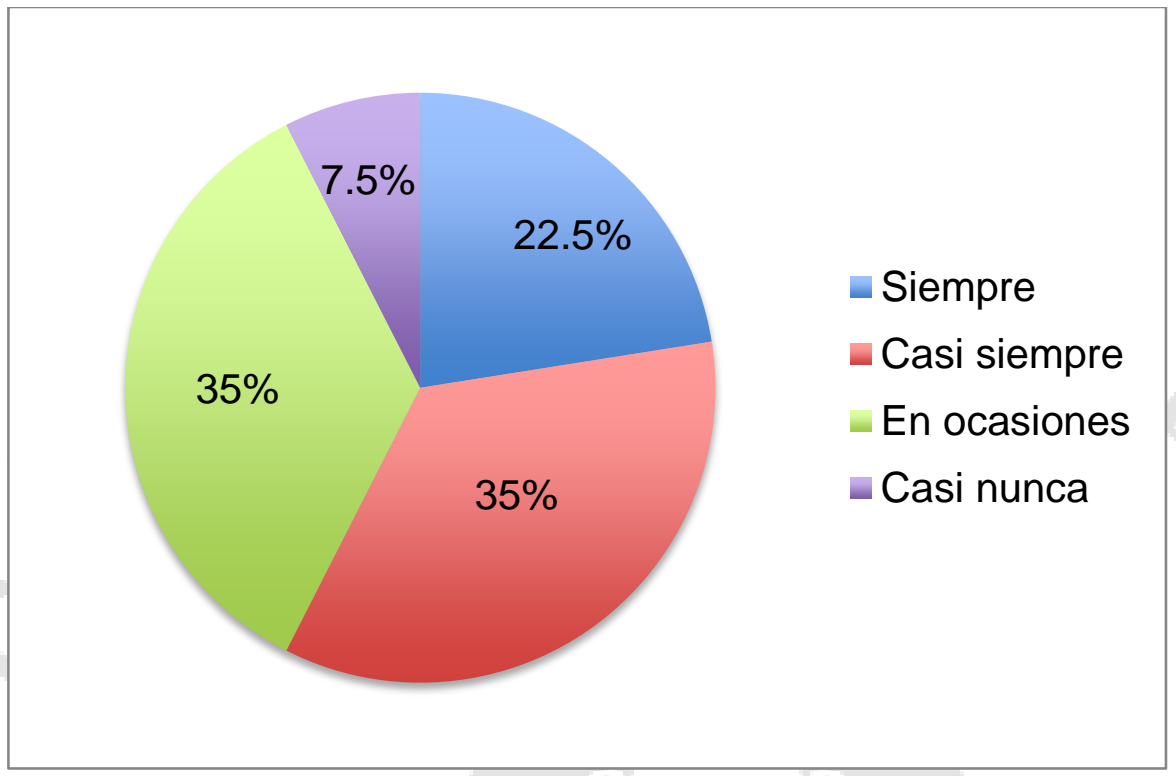

Fuente: Elaboración propia.

Gráfico 11: ¿Asiste a las actividades de integración?

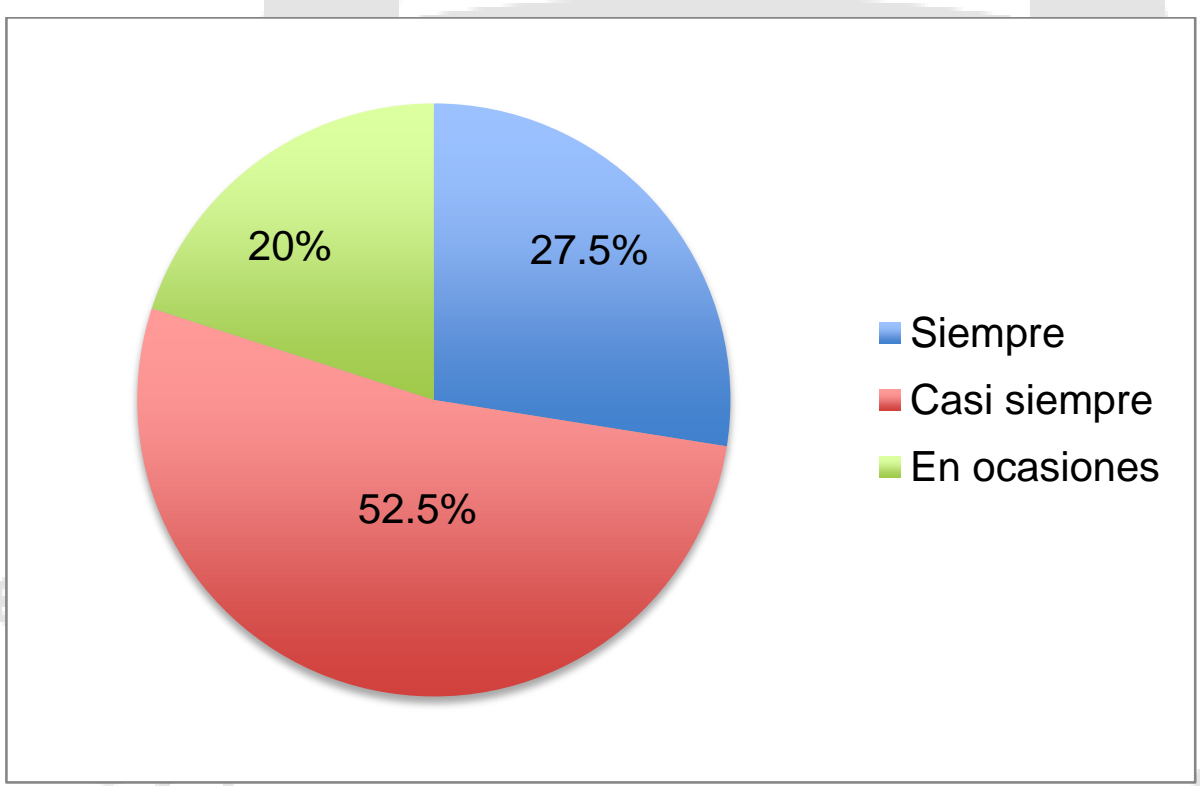

Fuente: Elaboración propia. 
Gráfico 12: ¿Conoce usted sobre la existencia del 'Modelo de Gestión de Recursos Humanos' en Osiptel?

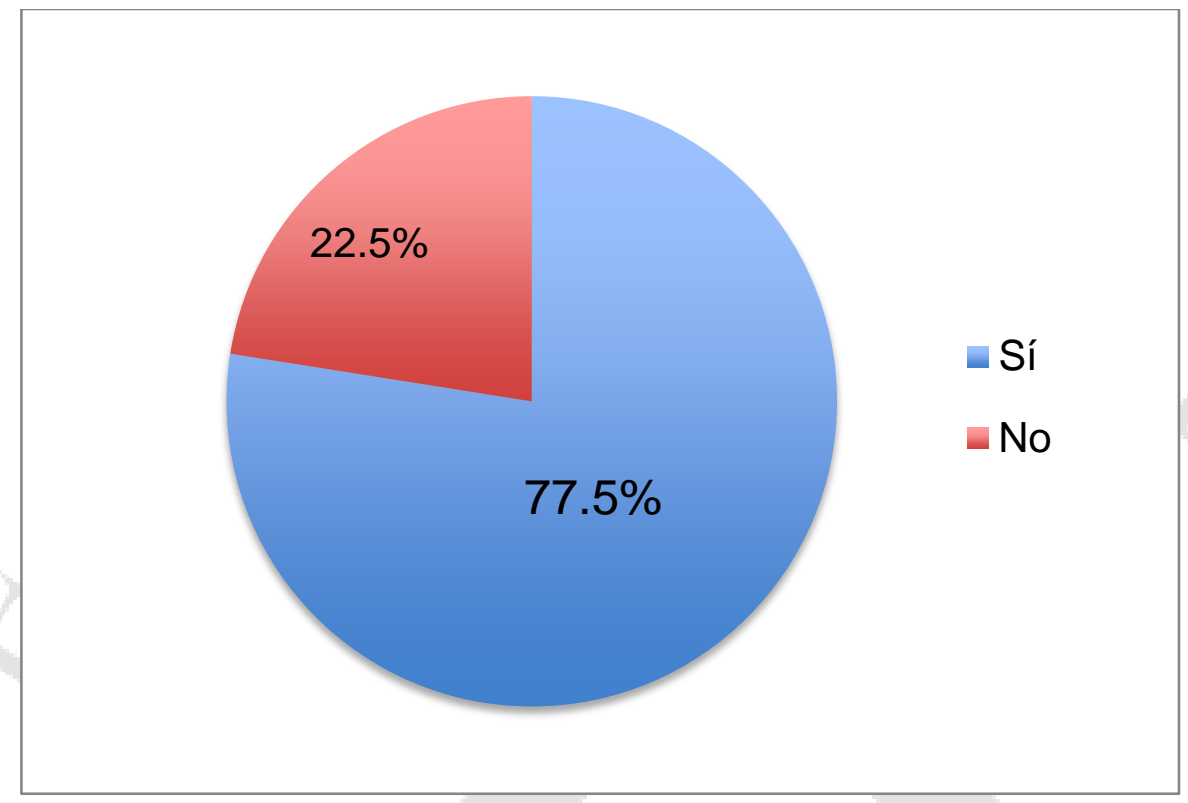

Fuente: Elaboración propia.

A aquellos colaboradores que marcaron la opción "No" en la pregunta anterior se les dio por concluida la encuesta. Dado que un $22.5 \%$ de colaboradores encuestados marcó esta opción, dicho porcentaje se repite en los gráficos de las siguientes preguntas bajo la opción "No respondió".

Gráfico 13: ¿Cuánto conoce usted sobre dicho modelo?

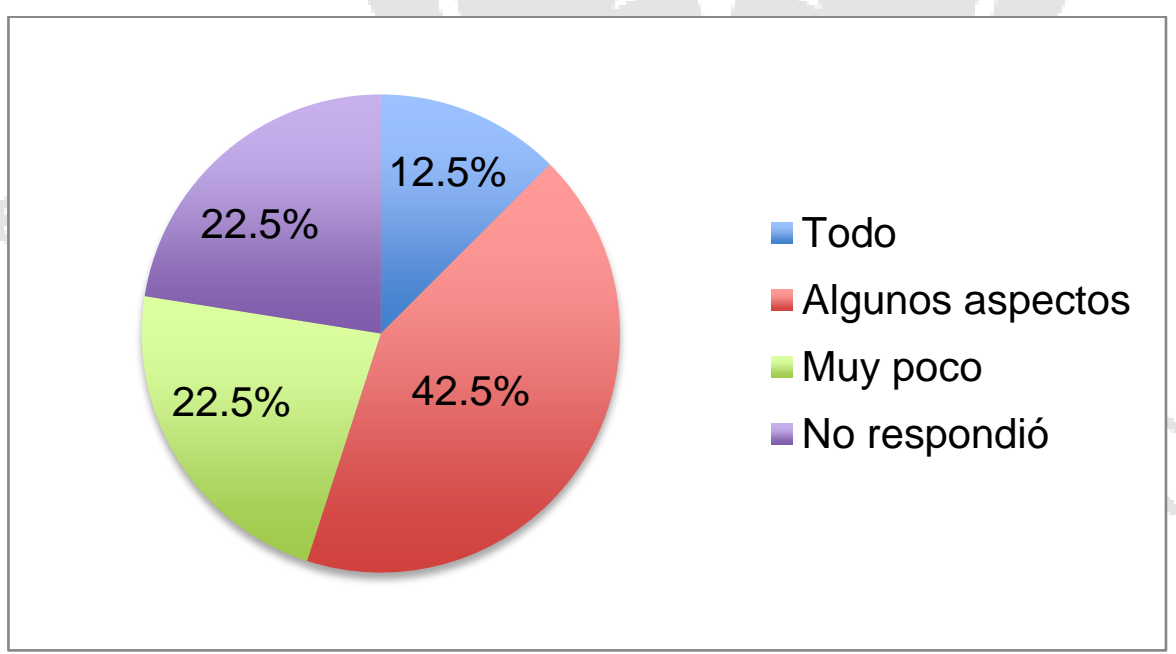

Fuente: Elaboración propia. 
Gráfico 14: ¿Cuánto conoce usted sobre la cultura organizacional que tiene Osiptel?

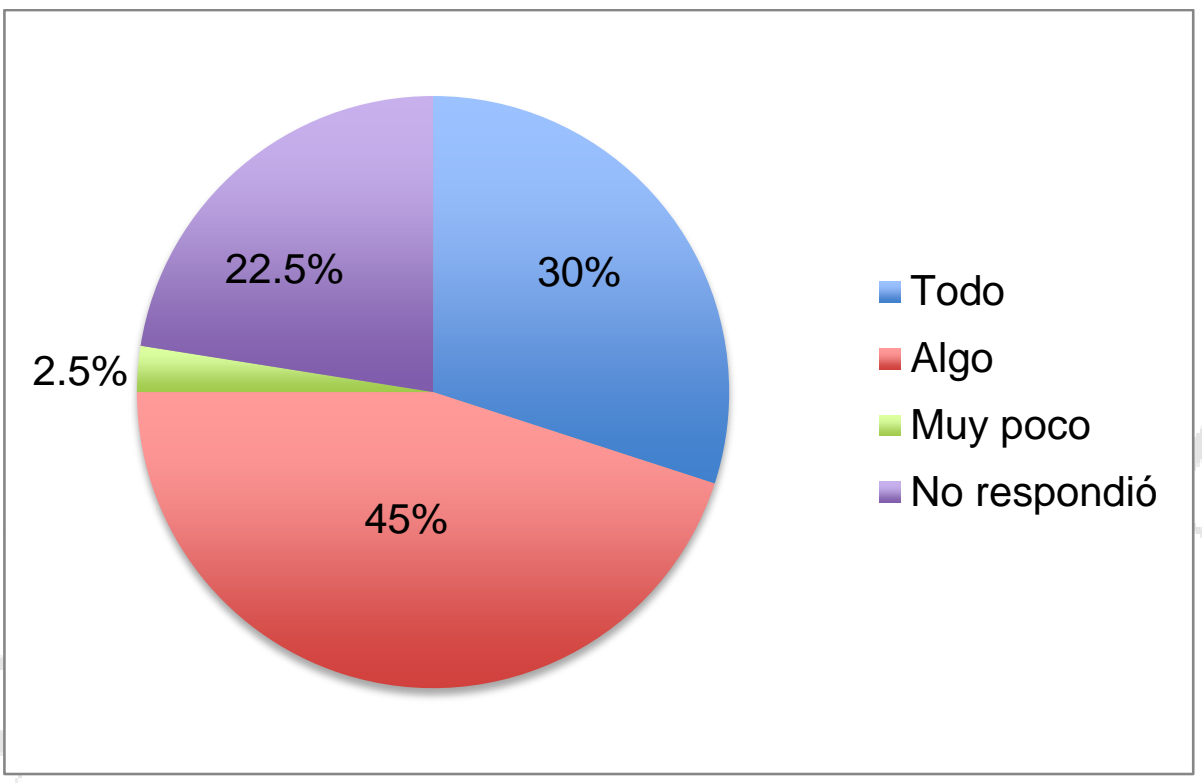

Fuente: Elaboración propia.

Gráfico 15: ¿Cuánto conoce usted sobre los seis valores institucionales de Osiptel?

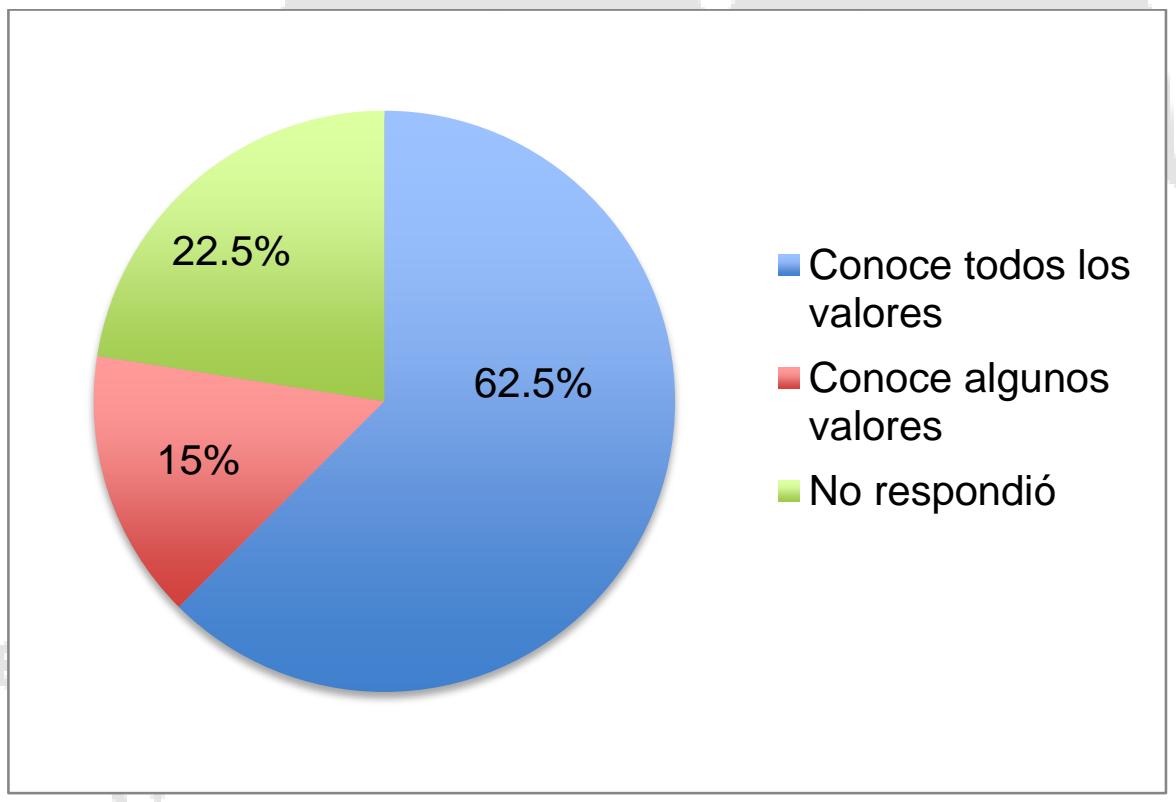

Fuente: Elaboración propia. 
Gráfico 16: ¿Cuánto cree usted que lo propuesto en el modelo concuerda con la realidad de la institución?

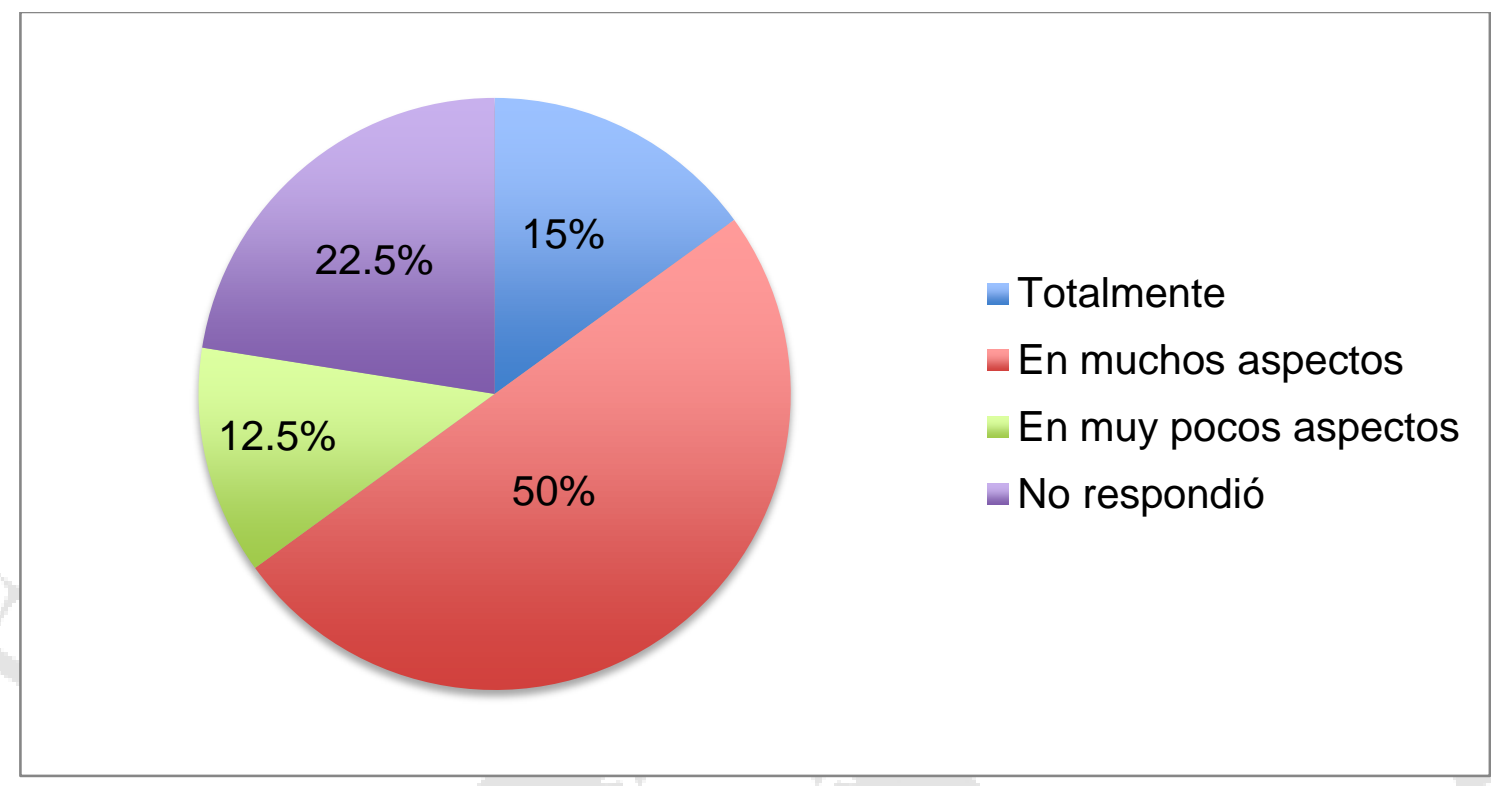

Fuente: Elaboración propia.

Gráfico 17: ¿Considera usted que este modelo ha sido suficientemente difundido y comunicado por el área correspondiente?

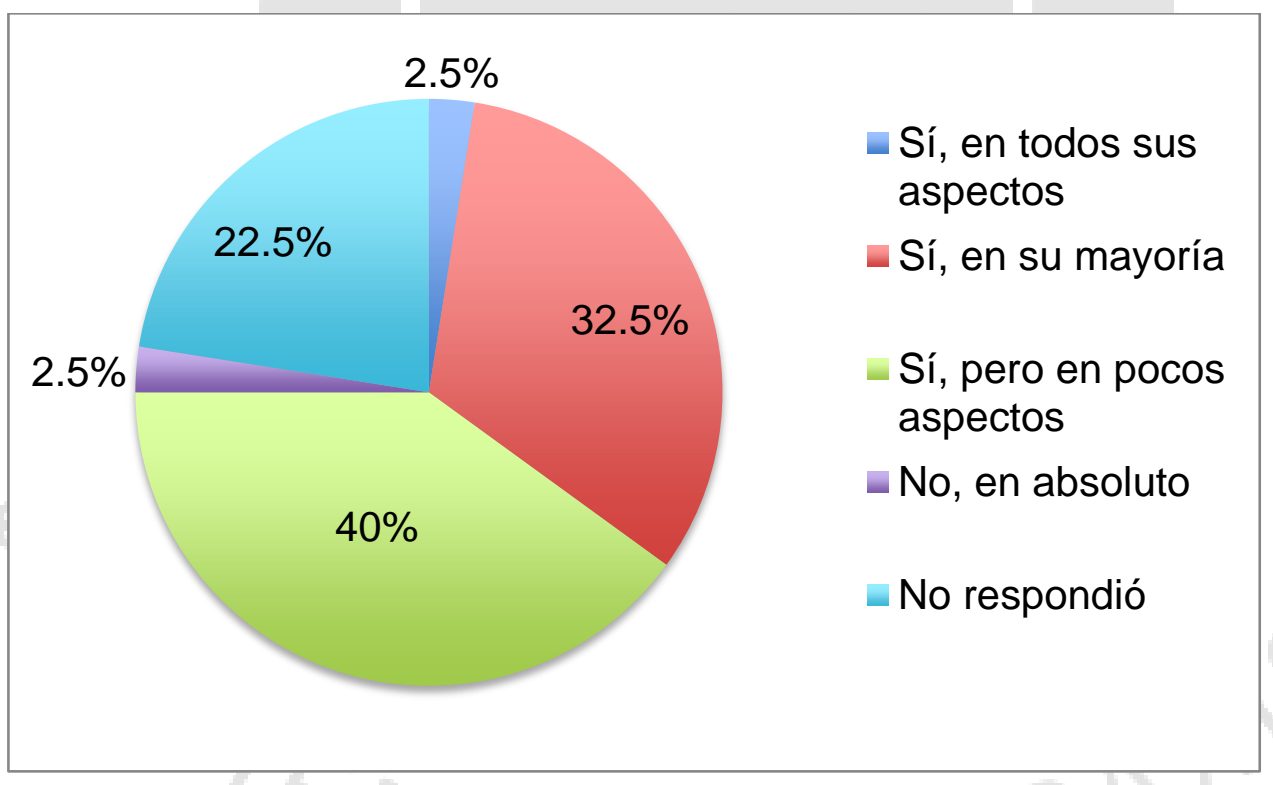

Fuente: Elaboración propia. 


\section{Anexo 2.2. Resultados en base a tiempo trabajando en la institución.}

Gráfico 17: Percepción de valoración del trabajo por colegas y superiores según el tiempo trabajando en la institución.

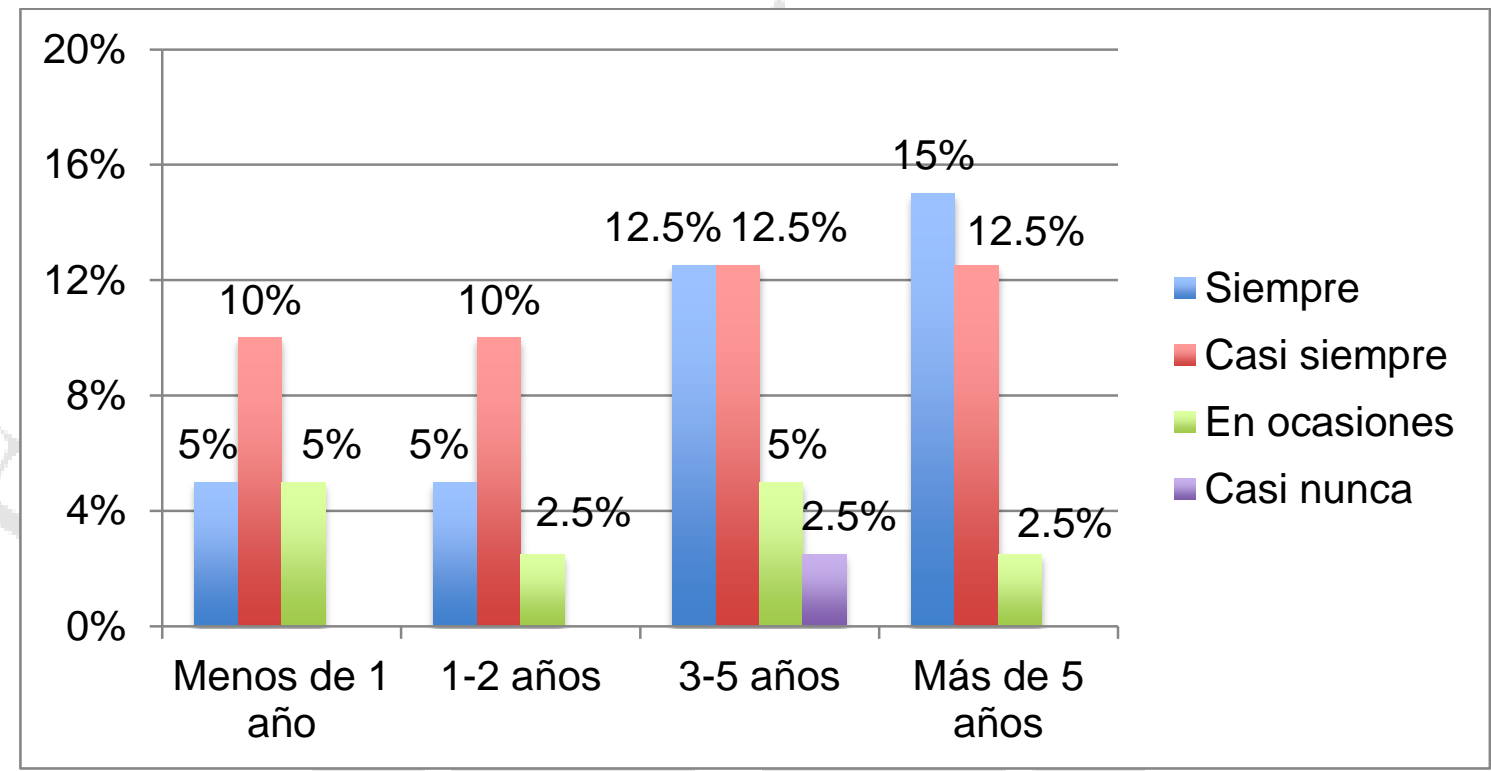

Fuente: Elaboración propia.

Gráfico 18: Percepción de escucha entre colaboradores según el tiempo trabajando en la institución.

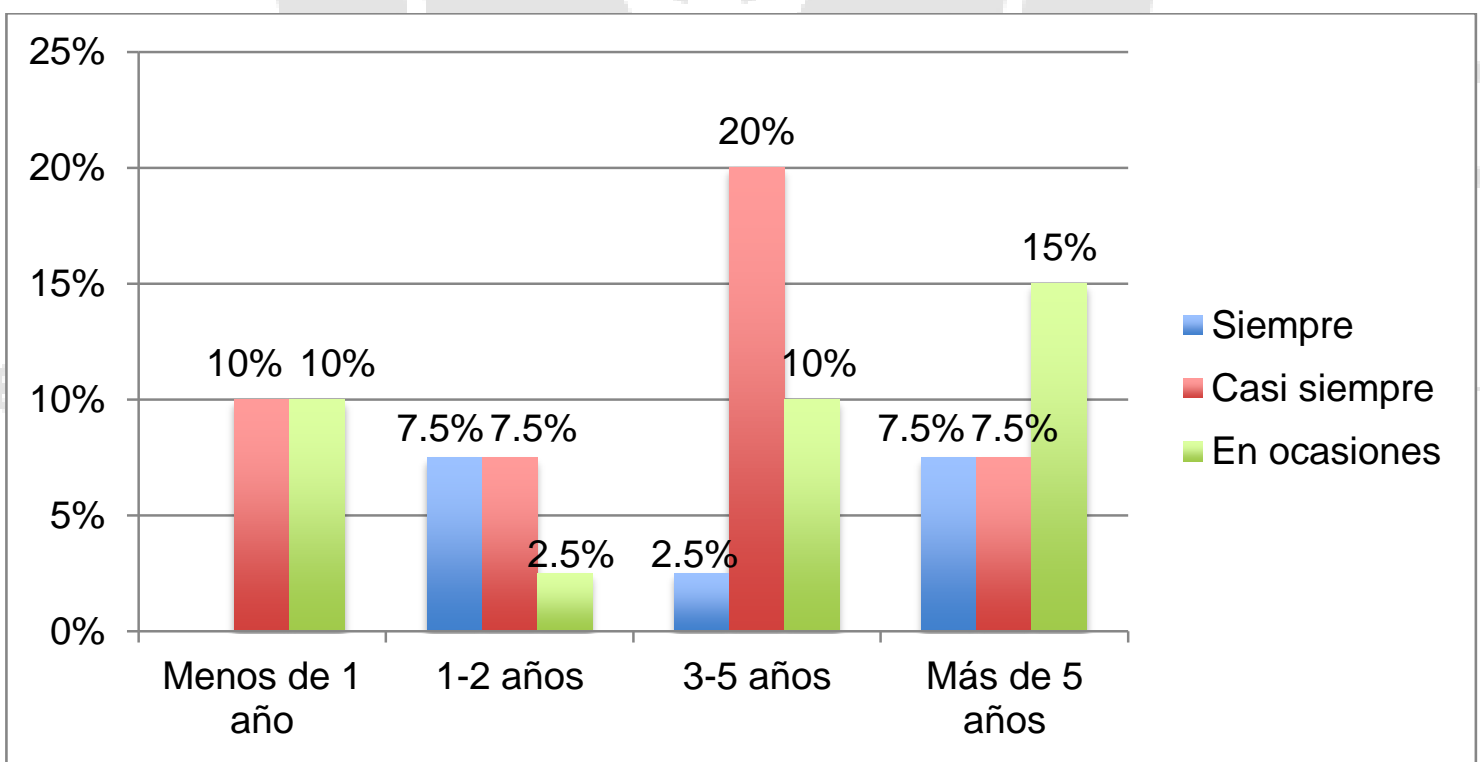

Fuente: Elaboración propia. 
Gráfico 19: Percepción de equidad en el trato de gerentes a colaboradores según el tiempo trabajado en la institución.

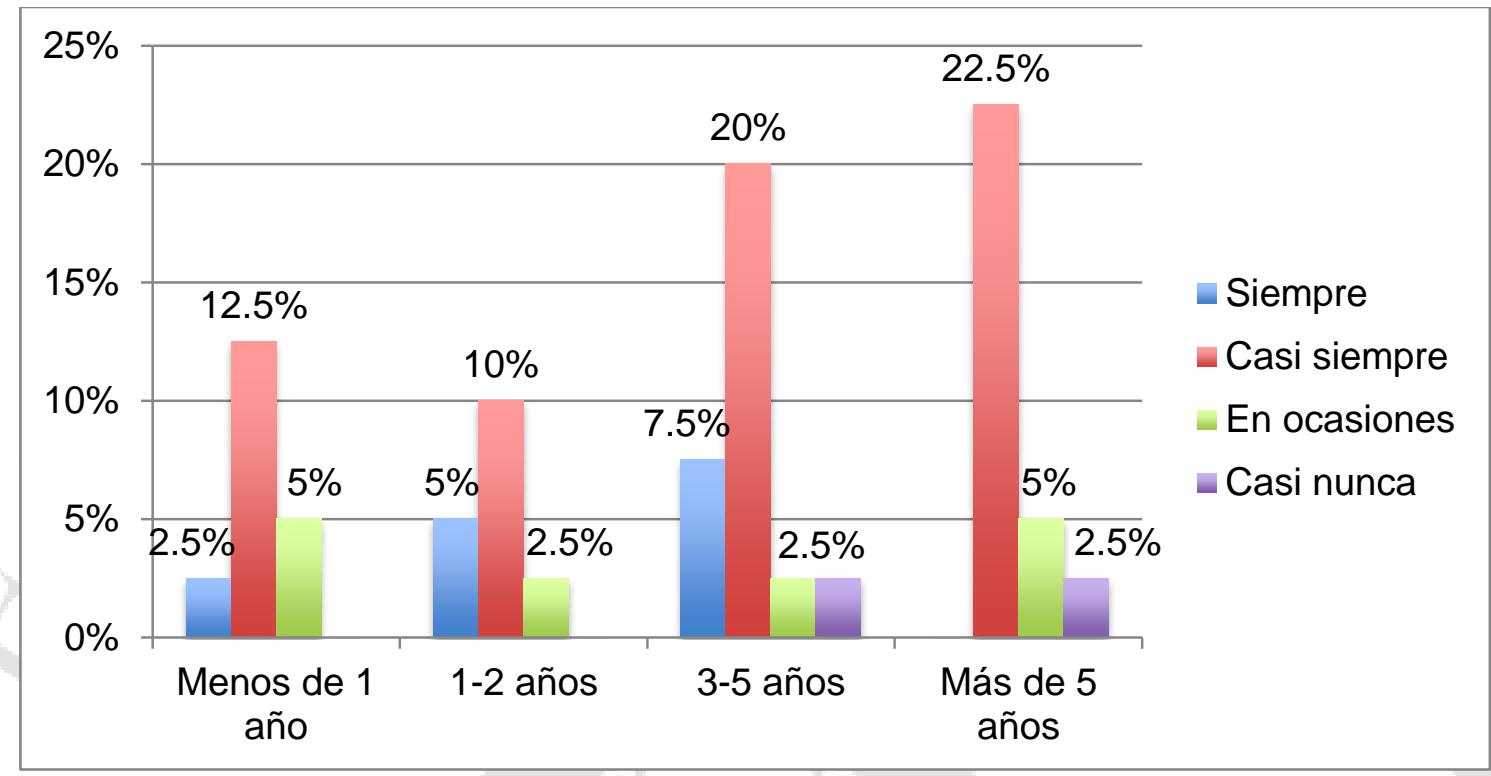

Fuente: Elaboración propia.

Gráfico 20: Percepción de reconocimiento del buen desempeño laboral según el tiempo trabajando en la institución.

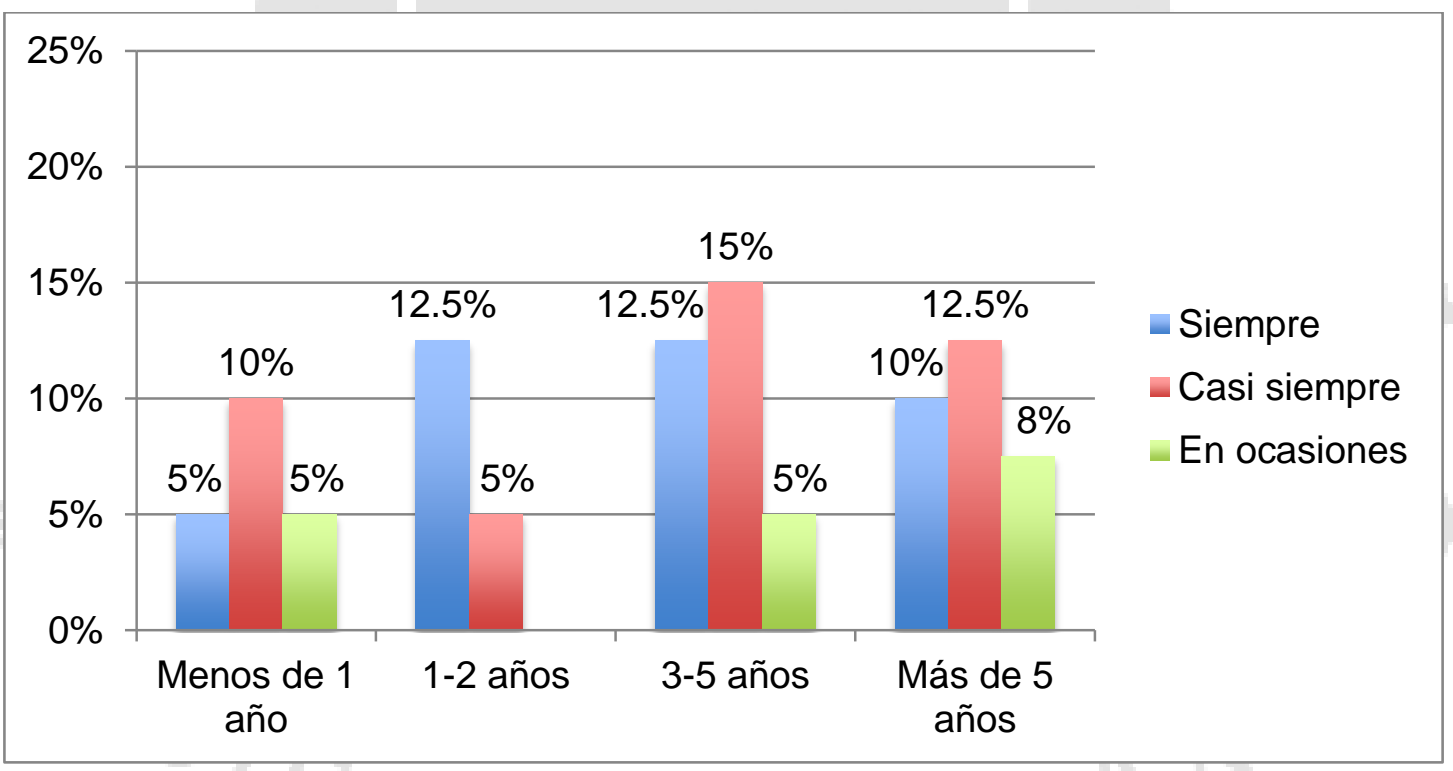

Fuente: Elaboración propia. 
Gráfico 21: Percepción del manejo adecuado de errores según el tiempo trabajando en la institución.

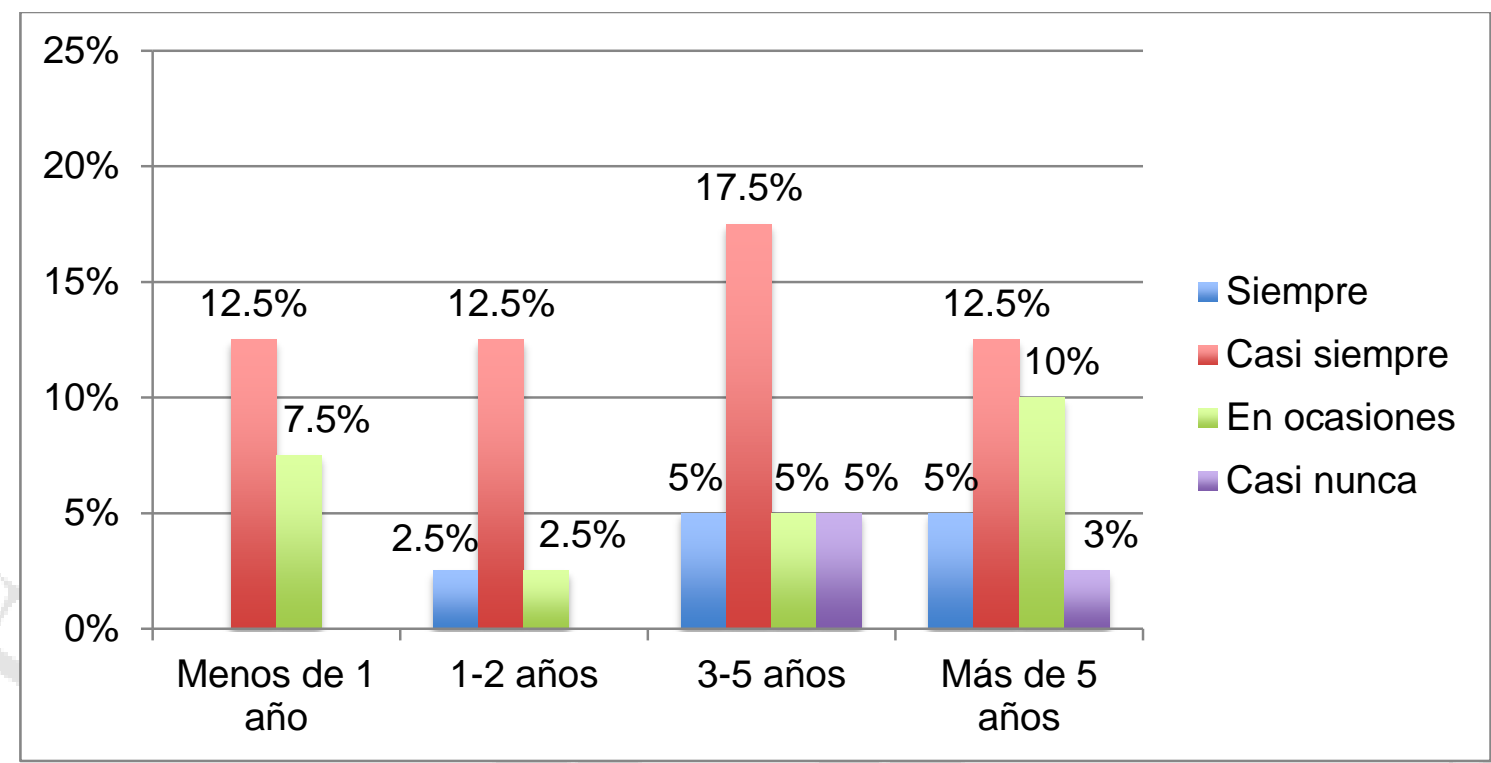

Fuente: Elaboración propia.

Gráfico 22: Percepción de la fluidez de la comunicación interna según el tiempo trabajando en la institución.

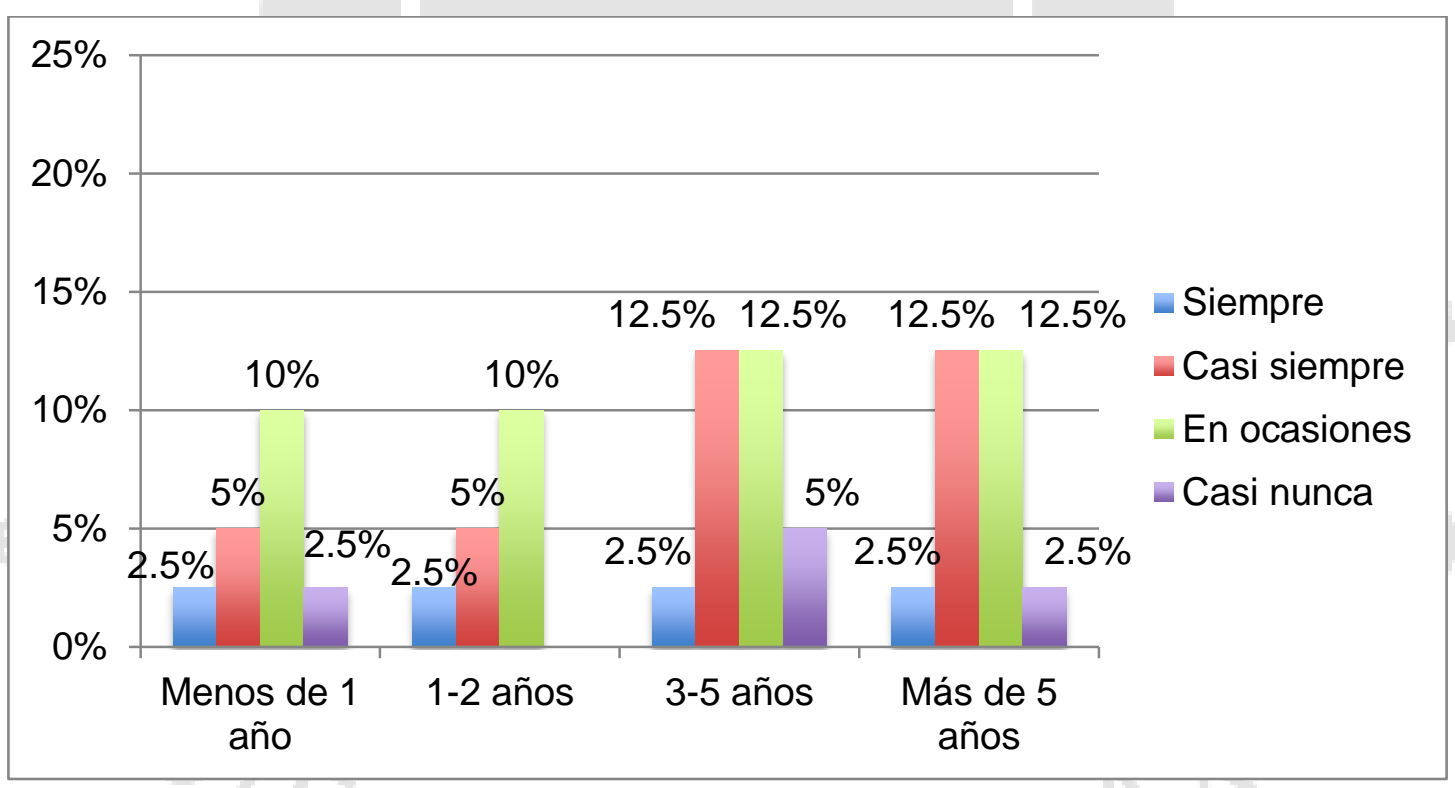

Fuente: Elaboración propia. 
Gráfico 23: Percepción del nivel de confianza entre colaboradores según el tiempo trabajando en la institución

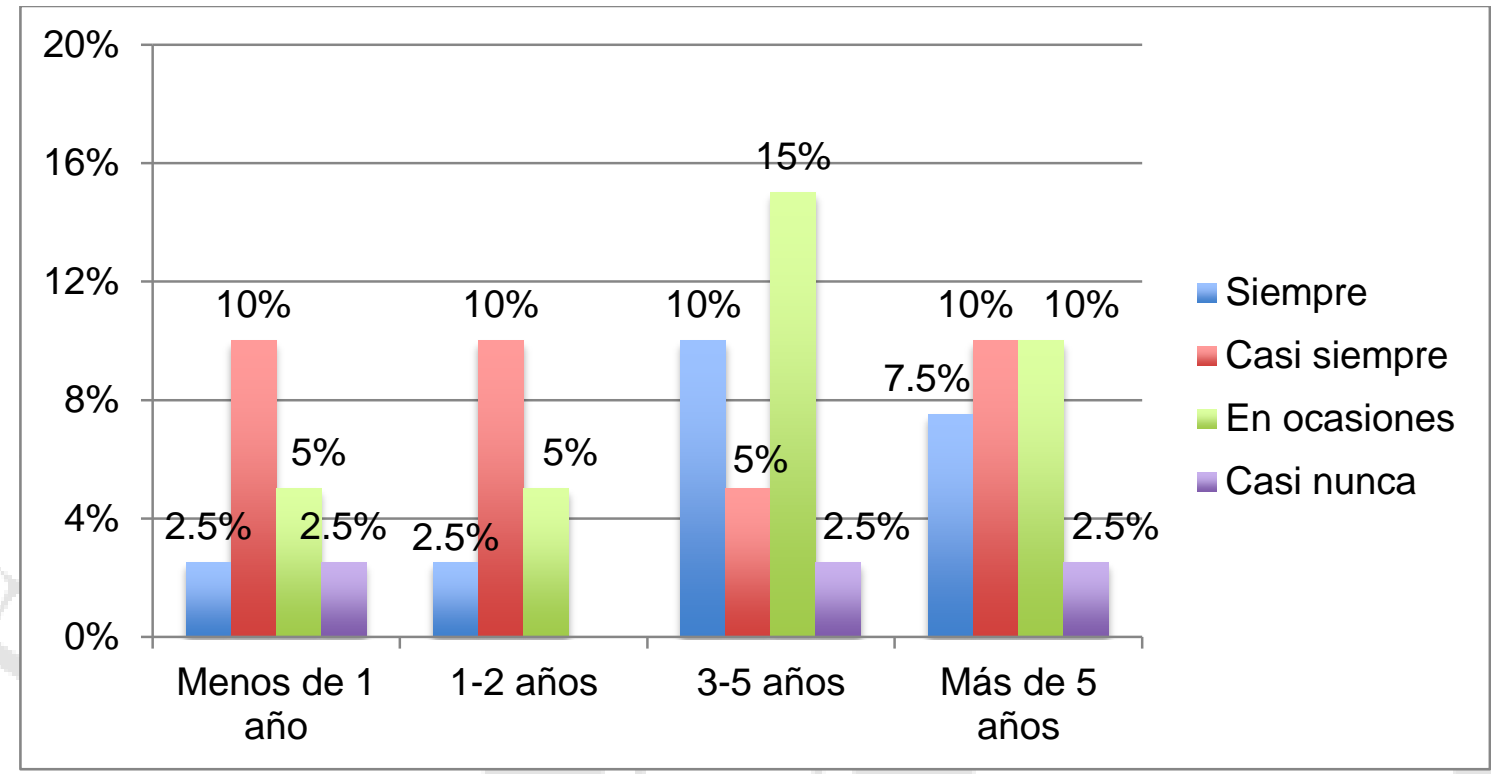

Fuente: Elaboración propia.

Gráfico 24: Frecuencia de asistencia a actividades de integración según el tiempo trabajando en la institución.

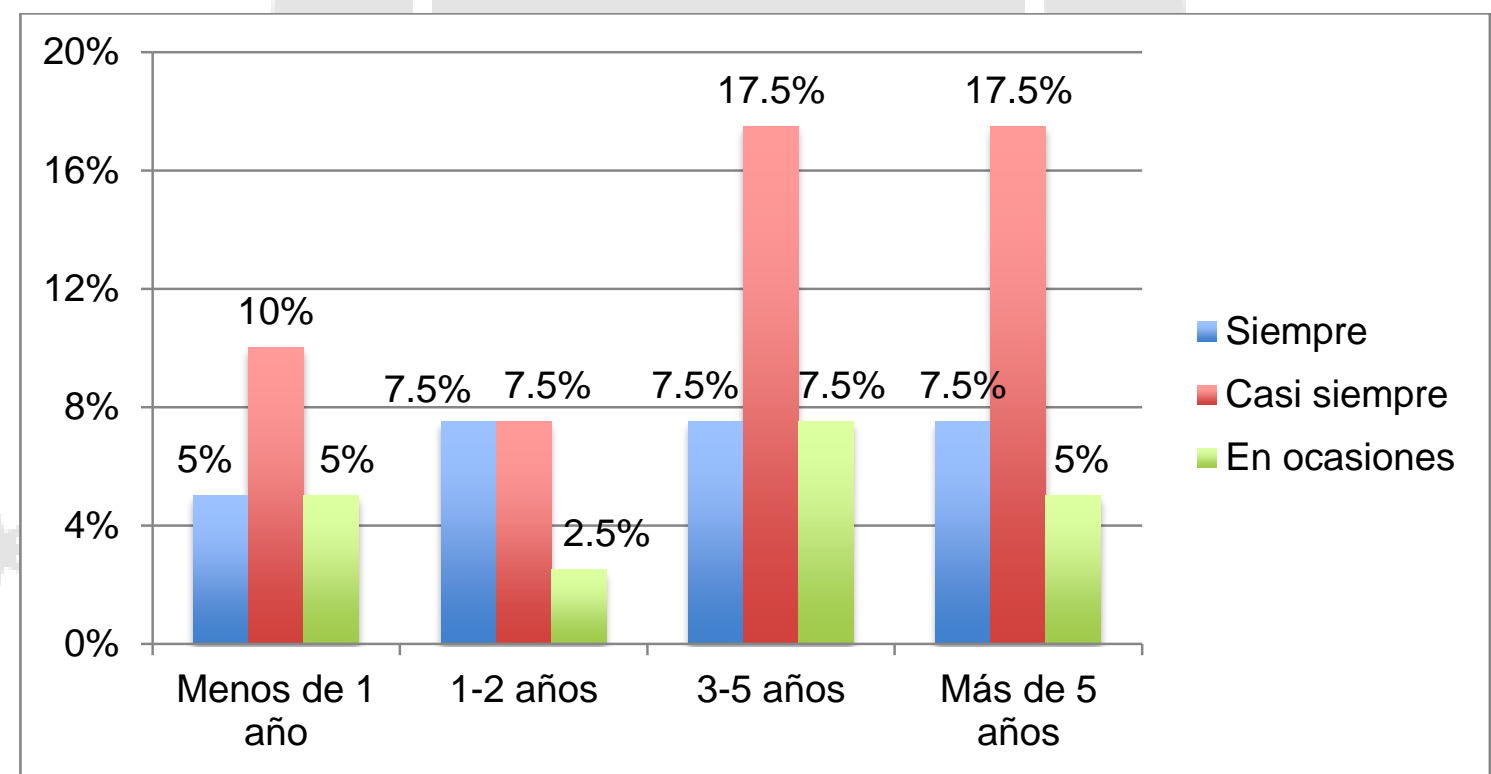

Fuente: Elaboración propia. 
Gráfico 25: Conocimiento sobre la existencia del Modelo de Gestión de Recursos Humanos según el tiempo trabajando en la institución.

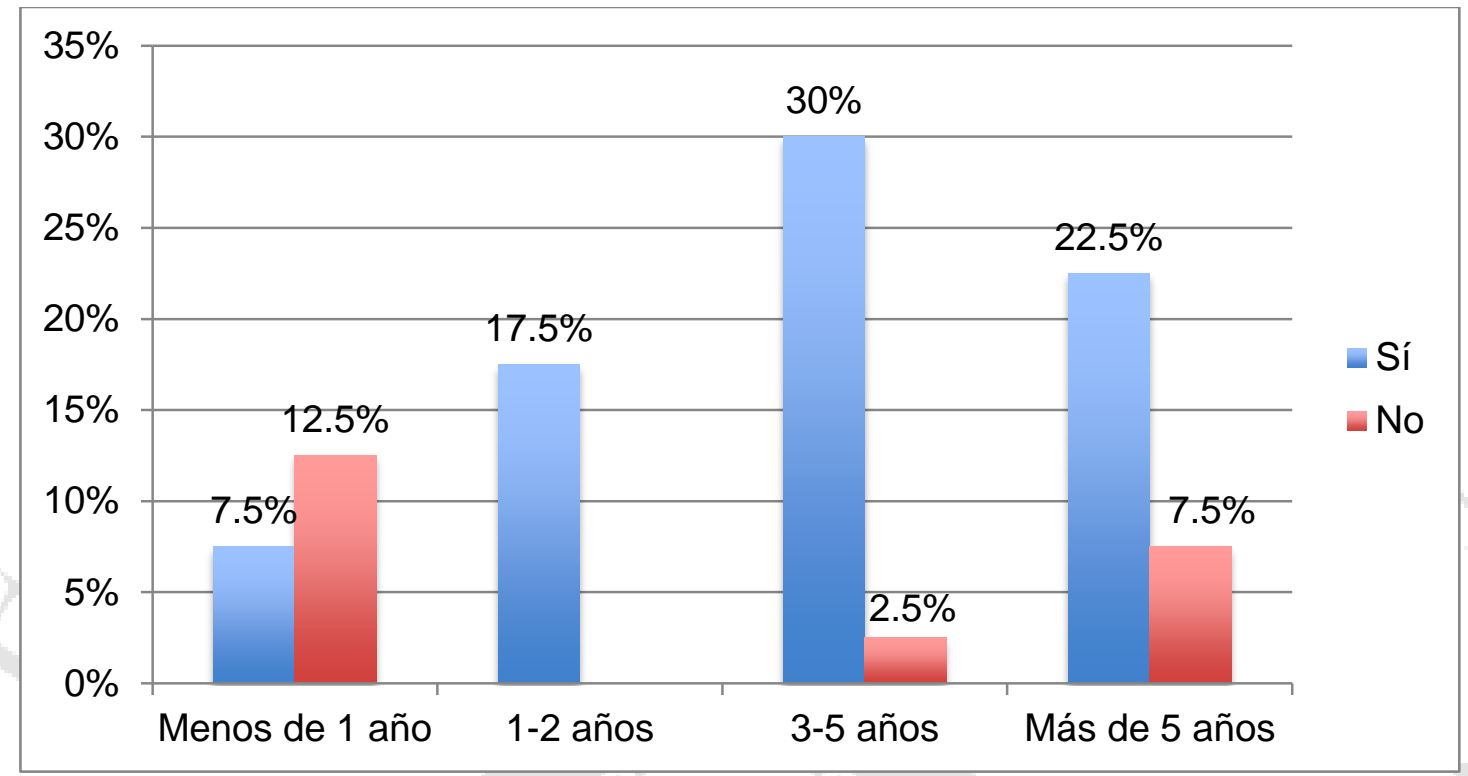

Fuente: Elaboración propia.

Gráfico 26: Magnitud del conocimiento sobre el Modelo de Gestión de Recursos Humanos según el tiempo trabajando en la institución.

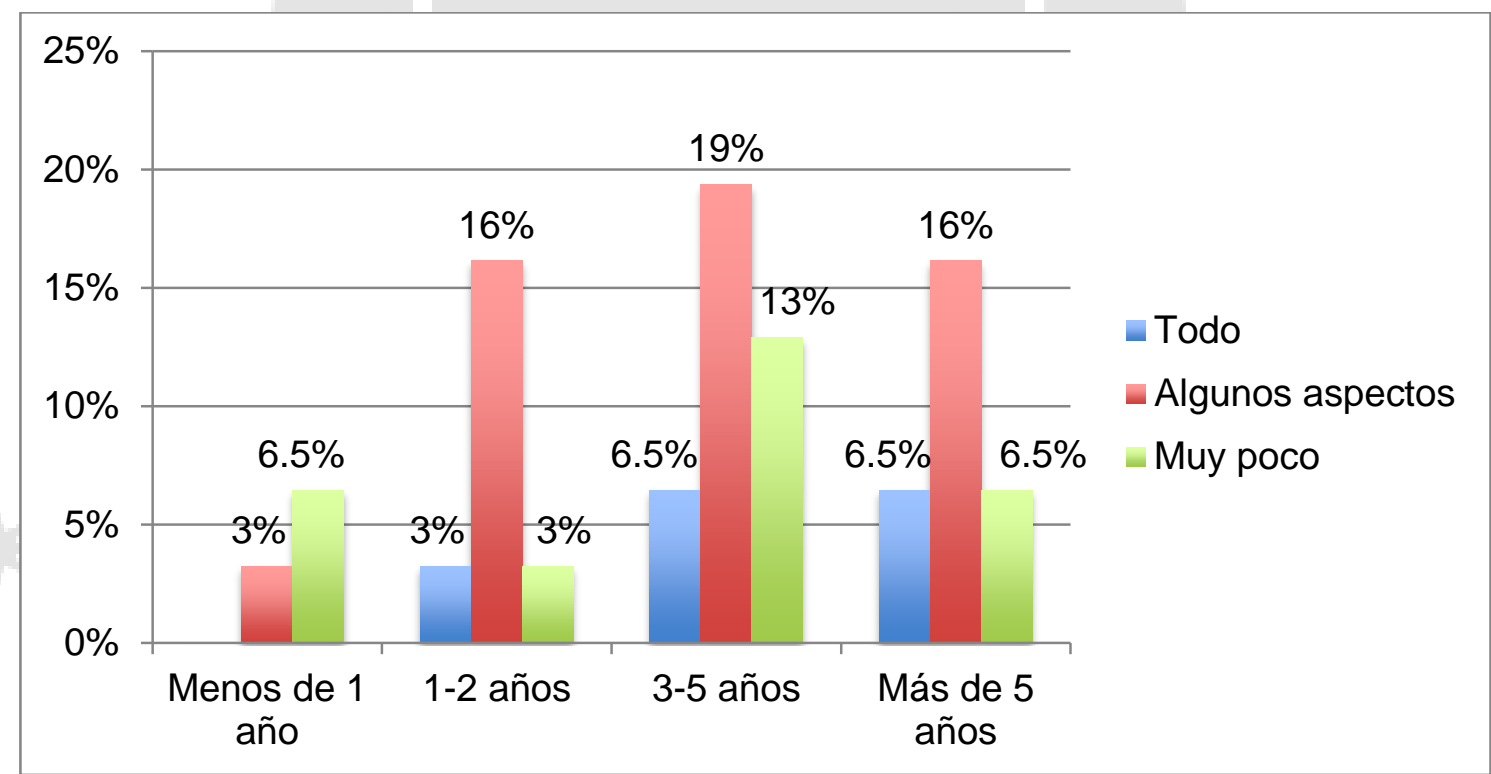

Fuente: Elaboración propia. 
Gráfico 27: Magnitud del conocimiento sobre la cultura organizacional de Osiptel según el tiempo trabajando en la institución.

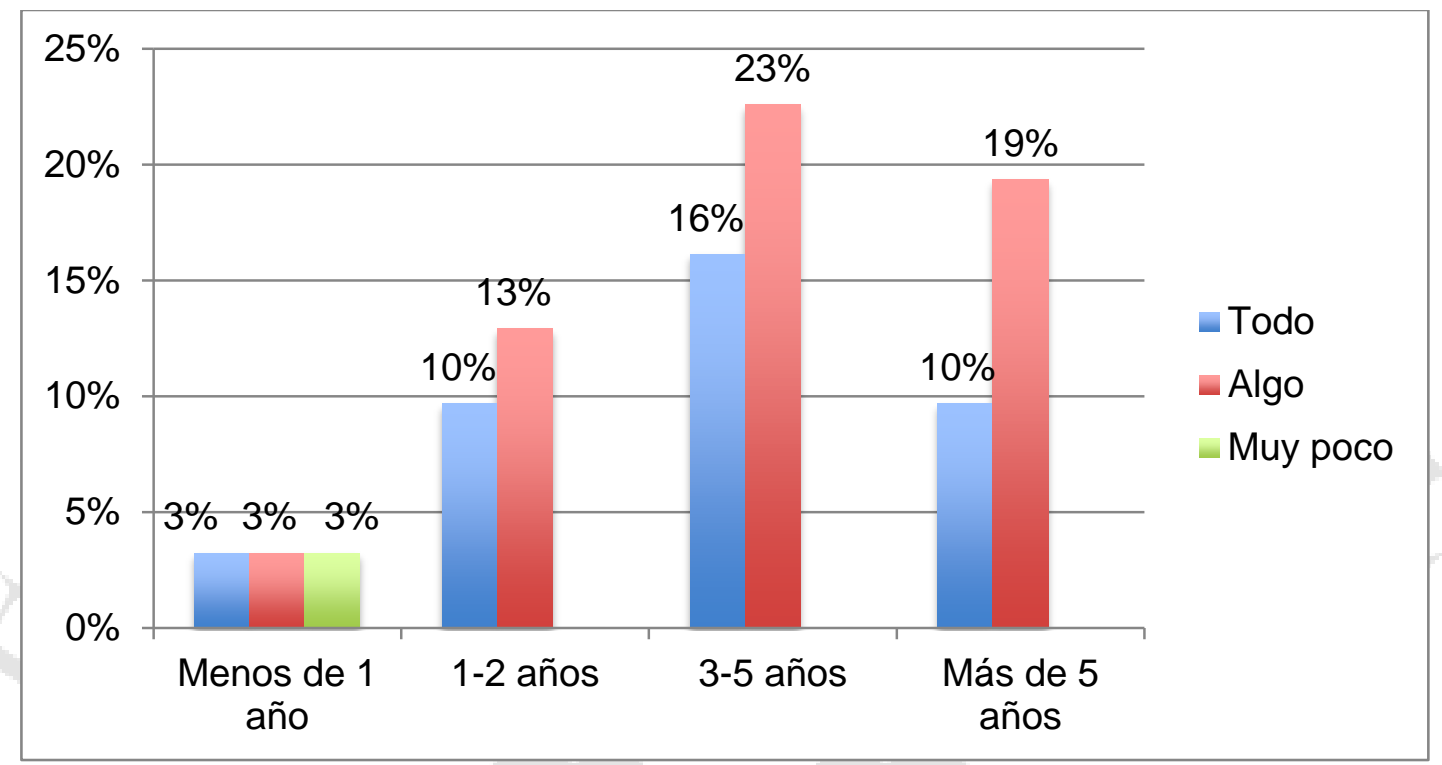

Fuente: Elaboración propia.

Gráfico 28: Magnitud del conocimiento sobre los valores institucionales de Osiptel según el tiempo trabajando en la institución.

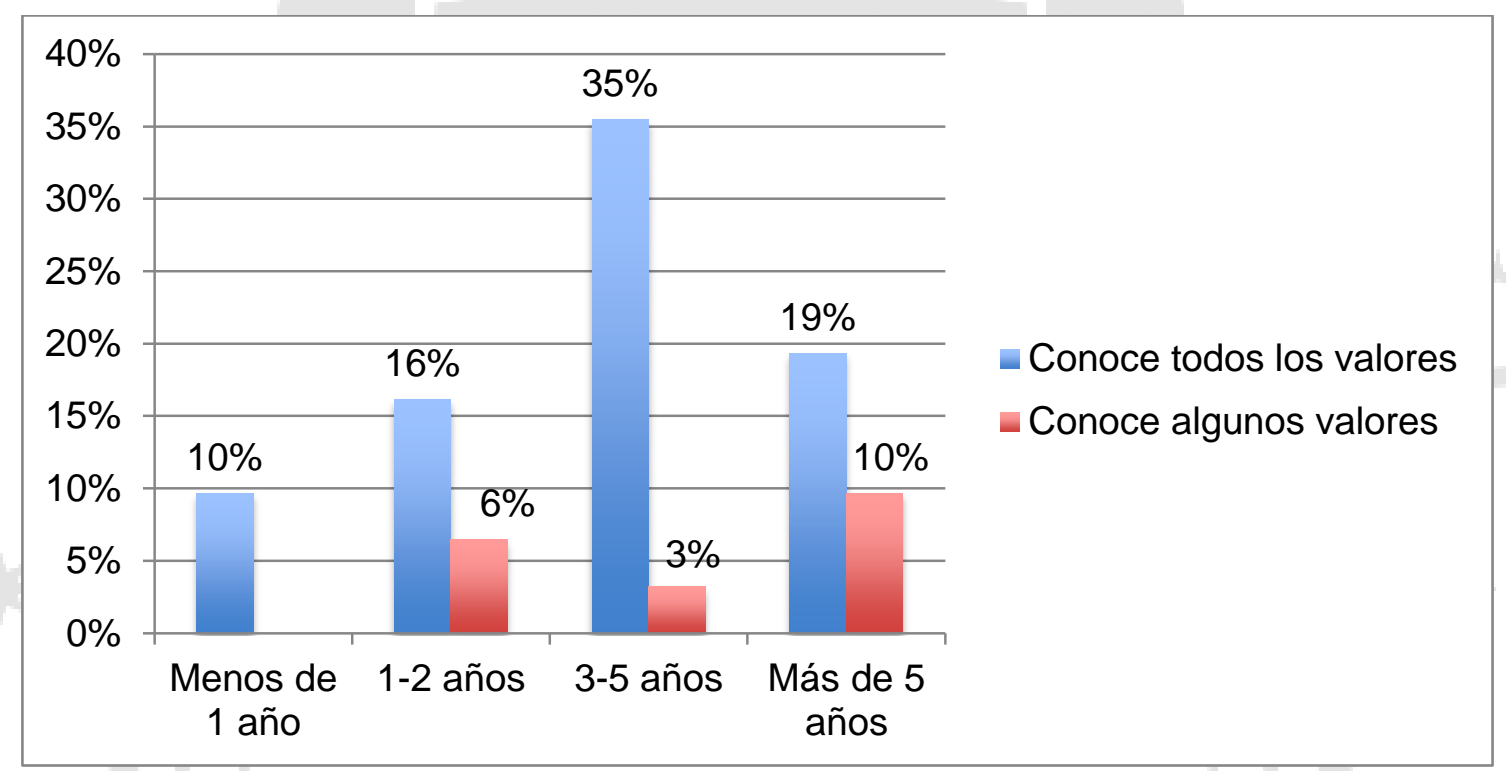

Fuente: Elaboración propia. 
Gráfico 28: Percepción de la magnitud de la concordancia entre lo propuesto en el Modelo de Gestión de Recursos Humanos y la realidad laboral en Osiptel según el tiempo trabajando en la institución.

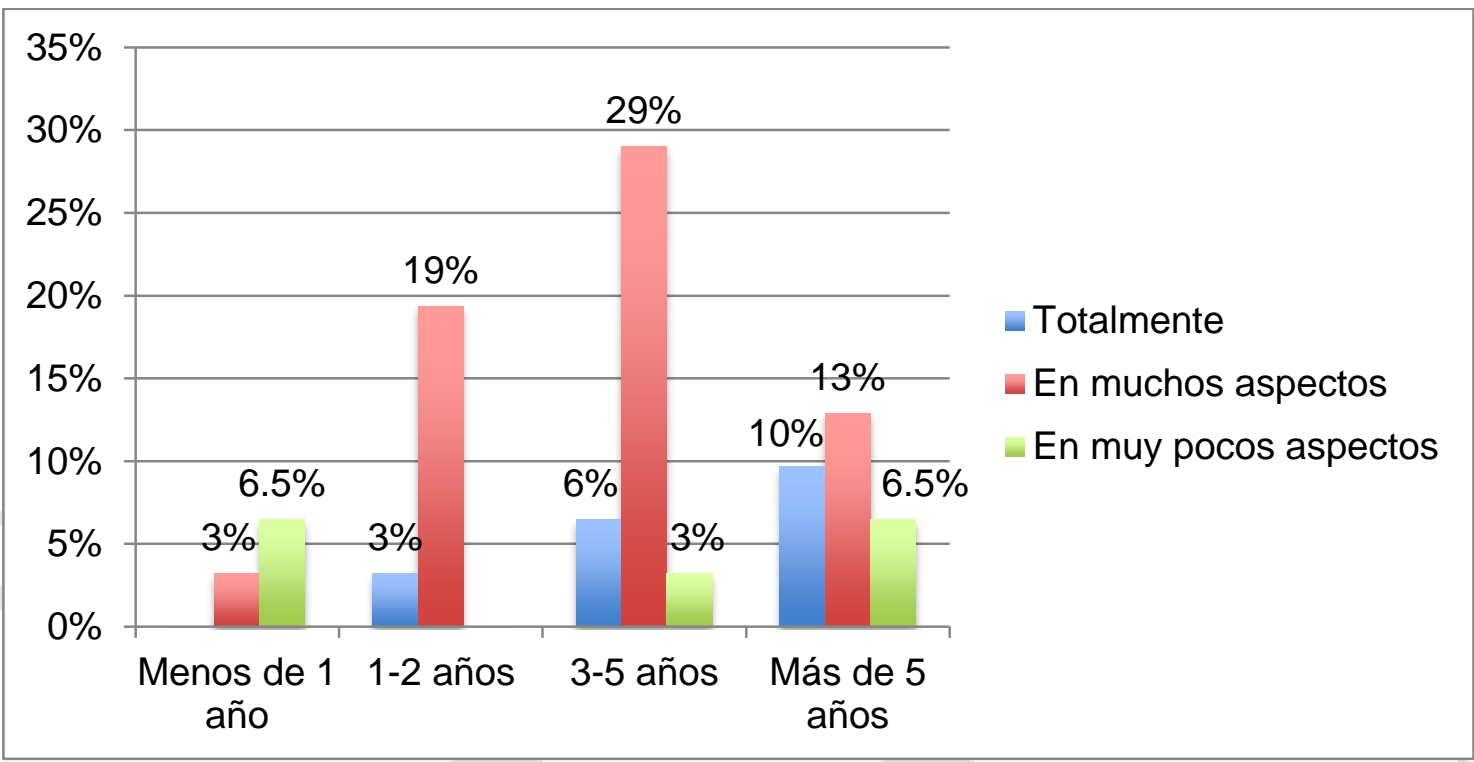

Fuente: Elaboración propia.

Gráfico 29: Percepción de la suficiencia de la difusión del Modelo de Gestión de Recursos Humanos de Osiptel según el tiempo trabajando en la institución.

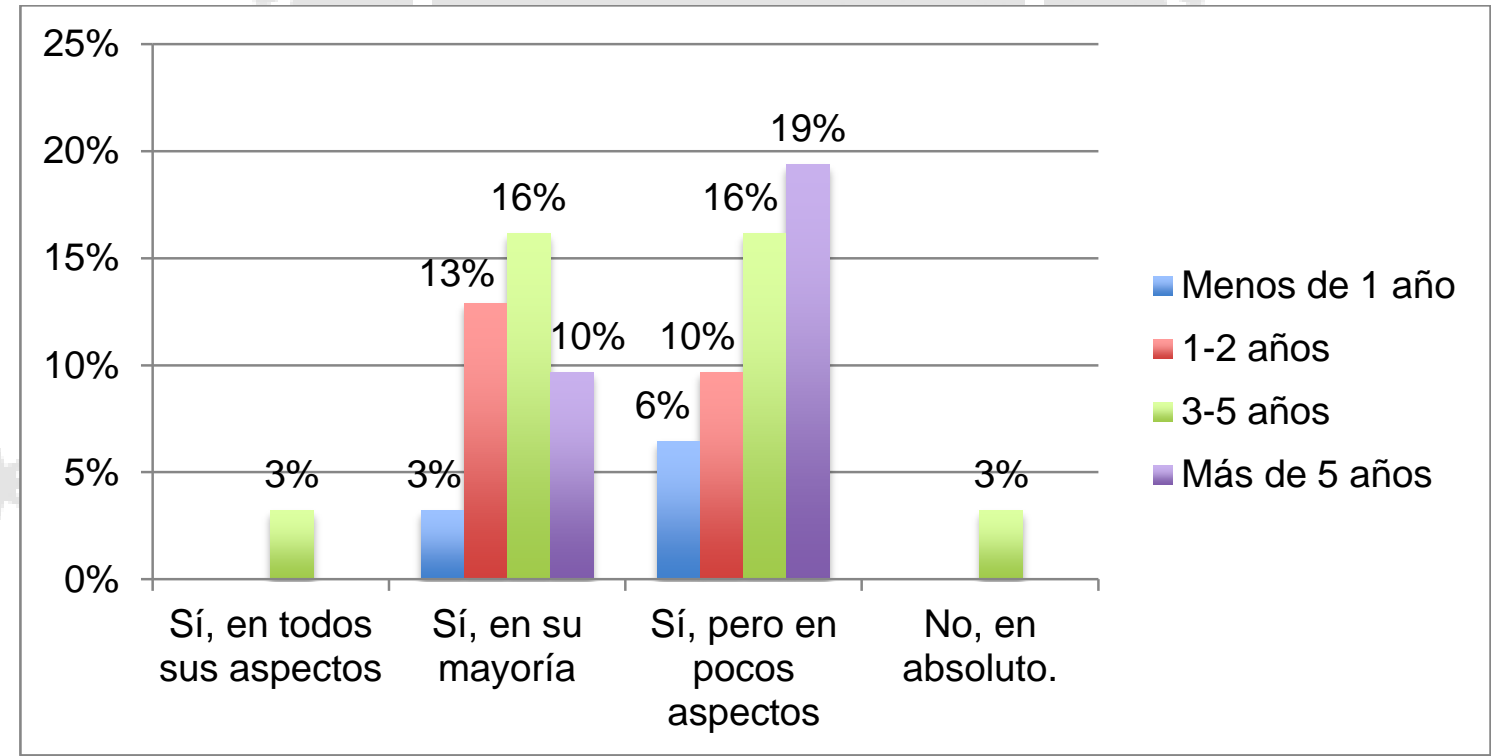

Fuente: Elaboración propia. 


\section{Anexo 3: Cuestionario de entrevistas a profundidad}

\section{Anexo 3.1 Cuestionario de entrevistas a gerentes.}

1. ¿Cómo describiría usted personalmente el clima laboral en la institución? ¿Qué aspectos destaca? ¿Qué cosas faltaría reforzar?

2. ¿Considera usted que existe involucramiento por parte de las gerencias en cuanto a la mejora del clima laboral en la institución? ¿Por qué lo considera así?

3. ¿Considera usted que existe una comunicación adecuada dentro de la institución? ¿Por qué? ¿Qué destaca sobre ella o qué faltaría para reforzarla?

4. ¿Conoce usted el modelo de gestión de recursos humanos propuesto por el área de administración y finanzas?

5. ¿Sabe usted en qué consiste el modelo de gestión de recursos humanos propuesto por el área de administración y finanzas ?

6. ¿Cómo se enteró usted sobre dicho modelo?

7. ¿Considera que este modelo es útil para la institución? ¿Por qué?

8. ¿Esta usted de acuerdo con la filosofía planteada en el modelo? ¿Por qué?

9. ¿Aplica usted acciones o filosofías basadas en el modelo propuesto? ¿Por qué?

10. ¿Considera usted que se aplica en la institución los seis valores de clima laboral propuestos en el modelo de gestión? ¿Por qué? ¿Qué faltaría para aplicarlos en su totalidad?

11. Ahora que ya conoce sobre el modelo, ¿considera usted a nivel personal que hay concordancia entre lo que el modelo propone y lo que se vive en la organización? ¿Por qué lo cree así?

\section{Anexo 3.2 Cuestionario de entrevistas a 'Doctores de Clima'.}

1. ¿Considera usted que existe concordancia entre el modelo de gestión planeado y lo que se vive en la institución? ¿Por qué lo considera así?

2. ¿Cuál ha sido la recepción de los colaboradores en cuanto al modelo de gestión propuesto? ¿Y cuál ha sido la de los gerentes?

3. ¿Considera usted que este modelo ha sido lo suficientemente difundido o comunicado internamente? ¿Por qué lo cree así?

4. ¿Qué aspectos destacaría usted que permiten que el modelo se cumpla?

5. ¿Qué aspectos faltaría reforzar para que el modelo se cumpla en su totalidad? 
6. ¿Considera usted que las altas gerencias están interesadas en saber e informarse sobre el modelo? ¿Por qué lo cree así?

7. ¿Considera usted que las altas gerencias son receptivas sobre la información que los doctores del clima les brindan luego de las actividades? ¿Por qué lo cree así?

8. ¿Considera usted que los colaboradores son receptivos sobre la información que los doctores del clima les brindan luego de las actividades? ¿Por qué lo cree así?

9. ¿Está usted de acuerdo con lo planteado en el modelo de gestión de recursos humanos? ¿Qué aspectos cambiaría o añadiría? 